1 Diet Quality Index for older adults (DQI-65): development and use in predicting

2

3

4

5 Nicole. Dorrington ${ }^{1}$, Rosalind. Fallaize ${ }^{1,2}$, Ditte.A. Hobbs ${ }^{1}$, Michelle. Weech ${ }^{1}$, Julie.A.

$6 \quad$ Lovegrove $^{1}$

7 adherence to dietary recommendations and health markers in the UK National Diet and

\section{Nutrition Survey}

${ }^{1}$ Hugh Sinclair Unit of Human Nutrition, University of Reading, Reading, United Kingdom, and ${ }^{2}$ School of Life and Medical Sciences, University of Hertfordshire, Hatfield, United Kingdom

Corresponding author: Julie A Lovegrove, Hugh Sinclair Unit of Human Nutrition,

Department of Food and Nutritional Sciences, University of Reading, Whiteknights, PO Box 266, Reading, RG6 6AP, United Kingdom, Tel: +44(0)118 378 6418, E-mail:

j.a.lovegrove@ reading.ac.uk

Running title: Diet quality index older adults

18

Keywords: Older adults; Elderly; Diet quality score; Cardiometabolic health; Healthy ageing

Abbreviations: 25(OH)D, 25-hydroxyvitamin D; AHEI-2010, Alternative Healthy Eating

Index-2010; BP, blood pressure; CHD, coronary heart disease; CRP, C-reactive protein; 
23 CVD, cardiovascular disease; DBP, diastolic blood pressure; DQI, diet quality index; DQI-65, 24 Diet Quality Index for Older Adults; FDQI-65+PA, Food-based Diet Quality Index for Older 25 Adults with Physical Activity; HDL-C, high density lipoprotein cholesterol; HEI, Healthy Eating Index; HEI-2015, Healthy Eating Index-2015; LDL-C, low density lipoprotein

27 cholesterol; MDS, Mediterranean Diet Scores; NDNS, National Diet and Nutrition Survey;

28 NFDQI-65, Nutrient and Food-based Diet Quality Index for Older Adults; NFDQI-65+PA,

29 Nutrient and Food-based Diet Quality Index for Older Adults with Physical Activity; SACN,

30 Scientific Advisory Committee on Nutrition; SBP, systolic blood pressure; T2D, type 2

31 diabetes; TC, total cholesterol; WC, waist circumference. 


\section{Abstract}

Diet quality indexes (DQIs) are useful tools for assessing diet quality in relation to health and guiding delivery of personalised nutritional advice, however existing DQIs are limited in their applicability to older adults (aged $\geq 65$ years). Therefore, this research aimed to develop a novel evidence-based DQI specific to older adults (DQI-65). Three DQI-65 variations were developed to assess the impacts of different component quantitation methods and inclusion of physical activity. The variations were: Nutrient and Food-based DQI-65 (NFDQI-65), NFDQI-65 with Physical Activity (NFDQI-65+PA) and Food-based DQI-65 with Physical Activity (FDQI-65+PA). To assess their individual efficacy, the NFDQI-65, NFDQI-65+PA and FDQI-65+PA were explored alongside the validated Healthy Eating Index-2015 (HEI2015) and Alternative Healthy Eating Index-2010 (AHEI-2010) using data from the crosssectional UK National Diet and Nutrition Survey (NDNS) rolling programme. Scores for DQI-65 variations, the HEI-2015 and AHEI-2010 were calculated for adults $\geq 65$ years from years 2-6 of the NDNS ( $n=871)$. Associations with nutrient intake, nutrient status and health markers were analysed using linear and logistic regression. Higher DQI-65s and HEI-2015 scores were associated with increased odds of meeting almost all of our previously proposed age-specific nutritional recommendations, and with health markers of importance for older adults, including lower body mass index, lower medication use and lower C-reactive protein $(\mathrm{P}<0.01)$. Few associations were observed for the AHEI-2010. This analysis suggests value of all three DQI-65s as measures of dietary quality in UK older adults. However, methodological limitations mean further investigations are required to assess validity and reliability of the DQI-65s. 


\section{Introduction}

The ageing global population ${ }^{(1)}$ poses challenges to all aspects of society ${ }^{(2)}$, most notably health and social care. To lessen this burden and support individuals to maintain their physical, social and mental wellbeing later in life, exploring ways to promote healthy ageing is of high priority. In particular, appropriate nutrition is considered an important factor in reducing risk of cardiometabolic disease, slowing loss of bone and muscle mass, preserving cognitive function, and helping to maintain physical and mental fitness in older age ${ }^{(3)}$.

Diet quality indexes (DQIs) are useful nutritional assessment tools, accounting for the complexity of dietary exposure and the principle that people eat foods and not nutrients ${ }^{(4)}$, that can be easily translated into food-based, dietary advice ${ }^{(5)}$. Their use is increasingly prevalent, with several DQIs being investigated within older adults ${ }^{(6-18)}$. For example, Mediterranean Diet Scores (MDS) have been inversely associated with risk of incident disability ${ }^{(15)}$ and with overall, coronary heart disease (CHD) and cancer mortality ${ }^{(8,13,16)}$ in longitudinal studies.

Moreover, US Healthy Eating Index (HEI) scores have been positively associated with components of the Fried et al. frailty phenotype ${ }^{(19)}$ and indicators of functional decline such as gait speed and knee extensor power cross-sectionally ${ }^{(17)}$.

Nonetheless, component choice and scoring method mean current, widely used, DQIs could be deemed unsuitable for older adults (aged $\geq 65$ years) whereby a range of key health outcomes related to mortality risk and quality of life, and impacts of physical and cognitive decline, should be considered. Specifically, MDS discourage high dairy intake, a food group beneficial for musculoskeletal health ${ }^{(20)}$ and associated with lower risk of type 2 diabetes $^{(21)}$ and cardiovascular disease (CVD) $)^{(22)}$, whereas the HEI disregards the importance of oily fish consumption, particularly long chain (LC) n-3 PUFA content, which has been associated with reduced cognitive impairment ${ }^{(23)}$, inflammation ${ }^{(24)}$ and risk of $\mathrm{CHD}^{(25)}$. Moreover, the 
Alternative Healthy Eating Index-2010 (AHEI-2010) includes three fatty acid components, resulting in strong associations with CVD risk $^{(26)}$, however overall dietary quality may not be reflected in scores and associations with other health outcomes may be limited.

To our knowledge, only one DQI specifically tailored to older populations exists, the US Elderly Dietary Index, for which scores have been cross-sectionally inversely associated with CVD risk ${ }^{(9)}$. However, it has not been widely explored nor validated and may be limited in its associations with physical function and sarcopenia by favouring only moderate protein intake (highest scores awarded for only 1-2 servings/week each of meat, fish or seafood and legumes) and excluding physical activity as high protein intake (1.0-1.2g/kg/day; equivalent to $\geq 3$ servings/day of meat, fish or seafood and legumes) has been associated with improved or reduced loss of muscle mass and strength ${ }^{(27)}$, and physical activity acts synergistically with protein to enhance its effect ${ }^{(28)}$. Moreover, current established and validated scores such as the HEI and MDS were developed for use in US and Mediterranean populations respectively, questioning the suitability within a UK population.

Therefore, this study aimed to develop three variations of an evidence-based DQI suitable for UK older adults (aged $\geq 65$ years) (DQI-65) that characterised an optimum dietary pattern, and assess i) their ability to predict adherence to our previously proposed age-specific nutritional recommendations for this population group ${ }^{(27)}$ and ii) associations with health markers of importance to older adults, using cross-sectional data. The novel DQI were explored alongside the validated HEI-2015 and AHEI-2010 to identify whether the new DQI65 s were better predictors of adherence to nutritional recommendations and health status.

\section{Methods}


DQI-65 development was based on the steps documented by Waijers, Feskens and Ocke ${ }^{(29)}$ with all decisions being made by an experienced registered nutritionist (JAL) and registered dietitian (RF), and a nutrition student (ND). Following a thorough evaluation of existing indexes identified in the current literature, it was decided that the primary DQI-65 would be comprised of the more frequently used combination of foods and nutrients, with physical activity added due to the range of health benefits in older adults ${ }^{(30)}$. However, it was deemed appropriate to develop two further variations in order to test the effect of including physical activity and the effect of exchanging nutrient components with food groups on the predictive value of the index. The three DQI-65s were: Nutrient and Food-based DQI-65 (NFDQI-65), which contained food groups and nutrients, NFDQI-65 with Physical Activity (NFDQI65+PA), which contained food groups, nutrients and physical activity, and Food-based DQI65 with Physical Activity (FDQI-65+PA), which contained solely food group components with physical activity.

\section{Choice of index components}

All decisions regarding choice of components and scoring criteria were guided by the nutritional recommendations for UK older adults ( $\geq 65$ years) proposed in our previous critical review, along with the practical food-based advice we devised ${ }^{(27)}$. Nutrients from our proposed age-specific nutritional recommendations were selected to be represented in the index if new recommendations had been set (i.e. protein, calcium, vitamin B12, folate and fluid) or if strong evidence supported their physiological role among older adults (i.e. dietary fibre, free sugars, MUFA, PUFA and SFA, LC n-3 PUFA, sodium, vitamin D and alcohol). Guidance from the UK Eatwell Guide ${ }^{(31)}$ was considered alongside these recommendations as 
consistency between dietary guidelines, where appropriate based on the identified age-specific evidence, would likely enhance adherence.

Twelve main components were devised, eleven of which were dietary components (a mixture of food groups and nutrients) and the twelfth represented physical activity (except for NFDQI-65 in which this was excluded).

Components 1-3 and 5-6 (fruit, vegetables, protein, low-fat dairy and wholegrain carbohydrates) represent nutrients identified as important to older adults and, in the case of protein, calcium, folate and vitamin B12, for which we proposed new, higher, recommendations ${ }^{(27)}$. Specifically, sufficient protein intake is important to support maintenance of muscle mass and strength among older adults, which diminishes with age ${ }^{(32)}$, and we found that evidence suggests older adults have higher protein requirements due to impaired absorption and utilisation ${ }^{(27)}$. Furthermore, dairy provides bioavailable calcium, an essential mineral required to minimise age-associated loss of bone mineral density ${ }^{(33)}$, and, along with animal proteins, is a good source of vitamin B12. Finally, fruit, vegetables and wholegrain carbohydrates provide dietary fibre and a wide range of vitamins and minerals (e.g., vitamins A, C, E and folate), supporting various physiological functions, and have been associated with lower risk of $\mathrm{CVD}^{(34,35)}$.

Component 4 (oily fish) was selected due to oily fish containing LC n-3 PUFAs and vitamin $\mathrm{D}$, and being associated with lower risk of $\mathrm{CHD}^{(25)}$.

Components 7-8 and 11 (free sugars, sodium, and alcohol) reflect nutrients in our previously proposed nutritional recommendations that are considered detrimental to health of older adults ${ }^{(27)}$. Specifically, high intake of free sugar containing foods may displace protein and micronutrient intake and increase risk of overweight or obesity ${ }^{(27)}$ and sodium intake is a major risk factor for hypertension ${ }^{(36)}$ and has been positively associated with systolic blood 
151 pressure (SBP) and diastolic blood pressure (DBP) in an elderly population ${ }^{(37)}$. Moreover,

152

153

154

155

156

157

158

159

160

161

162

163

164

165

166

167

168

169

170

171

172

173

sensitivity to the toxicity of alcohol increases with age ${ }^{(38)}$ and methodological limitations exist within age-specific evidence supporting benefits of light-to-moderate intake on health (as is appraised in the AHEI-2010), therefore discouraging alcohol consumption seems prudent in this age group ${ }^{(27)}$.

Component 9 (fat and fatty acids) reflects recommendations for dietary fat and fatty acids in our previous review and accounts for the variable relationships between different fatty acids and risk of chronic disease such as type 2 diabetes and CVD ${ }^{(27)}$. Specifically, SFA intake is discouraged and substitution with PUFA and MUFA is encouraged.

Component 10 (fluid) was selected as fluid intake is essential to prevent dehydration, which is associated with impaired cognitive and physical function, and to lower risk of constipation $^{(39)}$, which can impair appetite. Fluid intake is commonly low within this demographic due to impaired thirst sensation, poor renal function and fear of incontinence ${ }^{(40)}$, meaning it should not be overlooked within dietary assessments among older adults.

Finally, component 12 (physical activity) was included in the FDQI-65+PA and NFDQI-65+PA due to physical activity acting synergistically with protein to enhance muscle maintenance or synthesis in response to amino acids ${ }^{(28)}$, and its additional role in supporting weight maintenance, cardiovascular health and preventing loss of bone strength ${ }^{(30)}$.

No dietary variety component was included, but instead limitations were imposed regarding number of portions of certain foods, notably for vegetables, fruit and protein, preventing the maximum score being achieved without a varied diet. For example, for protein only $\leq 1$ portion each of legumes or nuts, dairy, and red meat were allowed per day, and for vegetables only $\leq 1$ portion each of legumes and tomato puree were allowed. These limitations 
were based on a consensus decision by the nutrition experts, taking into account the health benefits or detriments of each. Justification of these decisions are in Supplementary Table 1.

\section{Component measurement methods and recommendations}

Measurement methods chosen were either based on portions of representative foods or nutrient intakes. The NFDQI-65/NFDQI-65+PA and FDQI-65+PA measured fruit, vegetables, protein, low-fat dairy, wholegrain carbohydrates and fluid as portions of representative foods, and the NFDQI-65/NFDQI-65+PA measured free sugars, sodium, fat and fatty acid, and alcohol as nutrient intakes. In comparison, the FDQI-65+PA measured the free sugars, sodium, fat and fatty acid, and alcohol components as portions of representative foods which were selected based on main contributors to nutrient intakes in the NDNS and the panel's consensus decision.

Guidelines for food-group components were based on number of portions eaten, with a portion being a quantity considered as standard for UK adults (such as $80 \mathrm{~g}$ for fruits and vegetables $)^{(31,41,42)}$ to ensure applicability of the index to general UK portion sizes, or a quantity specified in SACN advice ${ }^{(25,43)}$. No age or sex-specific portion size guidance was identified and therefore portion sizes were generalised to older adults and both men and women. All portion weights were given as cooked or eaten. For nutrient components, quantitation was as mg, $\mathrm{g}$ or percentage of total energy intake (as relevant) and was guided by our previously proposed nutritional recommendations ${ }^{(27)}$. For the NFDQI-65 and NFDQI$65+\mathrm{PA}$, nutrient intake data for sodium and alcohol was used as mg and g, respectively, and free sugars, MUFA, PUFA and SFA were as percentage of total energy intake. Physical activity was assessed as minutes/day of moderate intensity activity which was calculated within the NDNS dataset from data collected using an NDNS specific self-reported 
questionnaire (Year 1) or the self-reported Recent Physical Activity Questionnaire (Years 2 onwards). Full details of physical activity assessment methods are detailed elsewhere ${ }^{(44)}$.

Required numbers of portions for each food-based component were set by analysing nutritional composition of specified foods and considering the evidence-base, as well as the quantity required to meet specific nutritional recommendations. For example, for protein the index recommendation is $\geq 3$ portions/day to promote protein consumption at each meal due to evidence of benefits of even protein distribution ${ }^{(45)}$, and as it was determined that 3 portions of protein, combined with specified quantities of other protein-rich foods in the index including low-fat dairy, oily fish and wholegrain carbohydrates, would help support an individual to meet the nutritional recommendation we proposed of $1.2 \mathrm{~g} / \mathrm{kg} / \mathrm{day}^{(27)}$. Similarly, for low-fat dairy, the recommendation of $\geq 3$ portions/day of the specified quantities was calculated as each portion provides $200-250 \mathrm{mg}$ calcium therefore providing up to $75 \%$ of our proposed daily calcium requirements of $1000 \mathrm{mg}$ which, in conjunction with other dietary sources of calcium, should allow this to be met. Recommendations for oily fish were based on the most recent UK Scientific Advisory Committee on Nutrition (SACN) advice ${ }^{(25)}$, with 1 portion/week meeting advised LC n-3 PUFA intake, and for physical activity were taken from the UK Physical activity guidelines for older adults ${ }^{(30)}$. For the remainder of the components, decisions were made from panel discussions, taking into account UK Eatwell guide recommendations in the case of fruit, vegetables and wholegrain carbohydrates due to their evidence-based nature and to promote consistency between guidelines where any reason to differ did not exist. Full explanations for all components are in Supplementary Table 1.

\section{Index scoring}


The components were scored in a manner that accounted for their evidence-based associations with health outcomes, negatively scoring those considered detrimental to health (i.e., lower intake receives higher score) and positively scoring those considered beneficial to health (i.e., higher intake receives higher score). Specifically, the fruit, vegetables, protein, oily fish, lowfat dairy, wholegrain carbohydrates, fat and fatty acids, fluid and physical activity components were positively appraised due to their proposed health benefits and the free sugar, sodium and alcohol components negatively appraised due to their proposed detrimental effects and the conclusions from our previous review ${ }^{(27)}$.

In the absence of qualitative evidence to suggest otherwise, components were equally weighted, with scores for each ranging between 0-10 points. This is in line with other widelyused DQIs, such as the HEI-2015 whose authors stated that dietary guidelines are to be considered as a whole and "all concepts are equally important"(46). A score of 10 was awarded for full adherence to each component recommendation, except for the fat and fatty acids component of the NFDQI-65 and NFDQI-65+PA, which were subdivided into two subcomponents (MUFA+PUFA:SFA ratio and SFA intake) each worth up to 5 points. A proportionate score was allocated for intakes between the minimum and maximum criteria using a linear slope, for example if an individual consumed 1 portion of fruit/day (for which the recommendation is $\geq 2$ portions/day) they would score 5 out of 10 points, whereas 1.5 portions of fruit/day would score 7.5. The maximum total score was 120 points for FDQI65+PA and NFDQI-65+PA and 110 points for NFDQI-65. Higher scores reflect greater adherence to the recommendations. Table 1. 
Ability of diet quality indicies to predict adherence to dietary recommendations and health

markers

The three DQI-65s were assessed alongside two widely used and validated scores: the

Healthy Eating Index-2015 (HEI-2015), which assesses adherence to the 2015-2020 US

Dietary Guidelines for Americans ${ }^{(46)}$, and the US-based AHEI-2010, which assesses intake of foods and nutrients associated with chronic disease risk $^{(26)}$.

Data was used for participants aged $\geq 65$ years $(n=1076)$ from years $2-6$ of the UK NDNS rolling programme $(2009 / 2010-2013 / 2014)^{(47)}$ (the most recent available NDNS data when the DQI-65 was developed). The NDNS is a UK cross-sectional survey of randomly selected

257 individuals aged $\geq 1.5$ years designed to assess dietary intake and nutritional status of a representative UK population. The methodology of the NDNS has been fully described elsewhere $^{(48)}$ and is summarised in the Supplemental Methods. Of importance, dietary assessment is based on 4-day diet diaries and physical activity measured via self-reported questionnaires on recent physical activity.

Individuals from year 1 were excluded due to the absence of physical activity data $(n=174)$, as were participants in years 2-6 where this data was not reported $(n=29)$, and those with energy intake $<600 \mathrm{kcal} /$ day $\left(600-4500 \mathrm{kcal}\right.$ reflected reasonable intake $\left.{ }^{(49)}\right)(n=2)$, leaving a total of 871 participants in the final analysis.

\section{Variables and measurement method}


In the present analysis, data for food and nutrient intake (excluding nutrients from vitamin, mineral or other dietary supplements) from the NDNS were used to calculate DQI-65 scores for each participant as per the index criteria (Table 1). Disaggregated foods were selected from the NDNS dataset where available (fruit, vegetables, legumes, meat, fish, nuts, and cheese), or data for individual food items was collated, using conversion factors and standard recipes from McCance and Widdowson's The Composition of Foods, $6^{\text {th }} \& 7^{\text {th }}$ Summary Editions $^{(50,51)}$ for obtaining cooked weights for wholegrain foods or disaggregating additional dishes where necessary to contribute to the DQI-65 calculations.

HEI-2015 and AHEI-2010 scores were also calculated for all subjects based on their original methodology $\mathrm{y}^{(26,46)}$ in a similar manner to the DQI-65s. Insufficient guidance was available for calculating the Elderly Dietary Index in our population ${ }^{(9)}$, so a comparison was not possible. Details of components in the HEI-2015 and AHEI-2010 are in Supplemental

\section{Table 2.}

\section{Ethical considerations}

The NDNS was conducted according to the guidelines laid down in the Declaration of Helsinki, and ethical approval for all procedures was granted by Local Research Ethics Committees covering all areas covered in the survey. All participants gave informed consent.

\section{Statistical analysis}

Mean component and total scores, and percentages of subjects achieving maximum component scores, were calculated for the DQI-65s, HEI-2015 and AHEI-2010 to assess adherence to index recommendations. Data are expressed as mean (SD) or percentages. 
291 Where mean (SD) is used, data is also represented as percentages to facilitate comparison

292 between scores.

Statistical tests were performed in SPSS Version 25.0 (SPSS Inc., Chicago, IL, USA), where P-values $<0.01$ were considered statistically significant on account of multiple testing. Data was visually inspected for normality. Variables identified as not normally distributed were log-transformed prior to analysis (see table footnotes). Sample weights were generated by the NDNS to adjust for differences in probability of selection and for non-response. The three types of weights used were: 1) interviewer weights, which were applied to demographic and dietary data to adust for non-response to the individual interview and food diaries, 2) nurse weights, which were applied to health outcome measures taken in the nurse visit (e.g. weight, blood pressure (BP)) to adjust for differences in participants and non-participants with these, and 3) blood sample weights, which were applied to all biomarkers of nutritional status and health outcomes based on biochemical measures to adjust for non-response to blood samples. Full details of how sample weights were calculated have been previously published $^{(52)}$.

To investigate the predictive ability of the DQI-65s in relation to the proposed nutritional recommendations for adults aged $\geq 65$ years from our previous review ${ }^{(27)}$, through which our decisions around components, portion or nutrient recommendations and scoring method could be explored, participants were classified by whether they met proposed nutritional recommendations ${ }^{(27)}$ based on daily nutrient intake from NDNS data. Associations between DQI-65s, HEI-2015 and AHEI-2010 scores and odds of meeting these nutritional recommendations for these categorical variables were assessed using binomial logistic regression analysis. 

2010 total scores and 1) biochemical markers of nutritional status (plasma 25-hydroxyvitamin D [25(OH)D], serum vitamin B12, plasma total homocysteine, haemoglobin concentration, plasma $\alpha$-tocopherol, plasma $\beta$-carotene), 2) anthropometric measures (BMI, obesity, waist circumference [WC], visceral obesity), 3) selected health indicators (medication use, longstanding illness, self-assessed health, activity limitation due to illness), 4) cardiometabolic risk factors (SBP, DBP, hypertension, total cholesterol [TC], fasting TG, low-density lipoprotein cholesterol [LDL-C], high-density lipoprotein cholesterol [HDL-C], TC:HDL-C, C-reactive protein [CRP], fasting glucose, glycated haemoglobin, classification of metabolic syndrome ${ }^{(53)}$ ) were assessed using linear regression analysis for continuous variables and logistic regression analysis for categorical variables. Missing data in the NDNS dataset meant different numbers of subjects were included in the health marker analyses. Since the maximum score available differed between scores, they were adjusted by proportional scaling for direct comparison between DQIs and to allow for a greater magnitude of change to be assessed than when considering a 1-point change. Therefore, a change in unadjusted B coefficient or odds ratio represents a 5\% change in DQI-65, AHEI-2010 and HEI-2015 scores (equivalent to a standard unit increase of 6 points for FDQI-65+PA and NFDQI-65+PA, 5.5 points for NFDQI-65 and AHEI-2010 and 5 points for HEI-2015 scores). odds of meeting nutritional recommendations were performed unadjusted. However, for health outcomes and biochemical markers of nutritional status, a step-wise approach for confounder adjustment was implemented to assess whether the DQIs predicted risk above and beyond other potential modifying factors. Confounders adjusted for were: age and sex (model 1), model 1 confounders plus BMI, WC, supplement use (nutrient biomarker analyses only), BP and/or lipid lowering medication (where applicable) and smoking status (model 2), and 
model 2 confounders plus income, marital status and education level (model 3). Unless specified, the results discussed are from the most adjusted model.

\section{Results}

\section{Characteristics of study population, and DQI total and component scores}

The mean age of the 871 subjects included in the analysis was 74 (7) years, and $44.2 \%$ were men. Study population characteristics are detailed in Table 2.

Mean total DQI-65 scores were 71.8 (15.1) out of 120 for the FDQI-65+PA (59.8\%), 68.1 (14.4) out of 120 for the NFDQI-65+PA (56.8\%) and $61.6(12.8)$ out of 110 for the NFDQI-65 (56.0\%). Mean component scores in all DQI-65s were $\geq 7$ out of 10 for vegetables, fruit, protein, fluid and sodium, reflecting greater adherence to these recommendations, whereas they were $\leq 3$ out of 10 for low-fat dairy and NFDQI-65/NFDQI-65+PA free sugars (Figure 1). Correspondingly, $\geq 50 \%$ of subjects scored maximum points for the sodium component in all DQI-65s, alcohol in the FDQI-65+PA and physical activity in the FDQI65+PA/NFDQI-65+PA. Conversely, a $\leq 10 \%$ of subjects scored maximum points for protein, low-fat dairy, wholegrain carbohydrates and NFDQI-65/NFDQI-65+PA fat and fatty acids, suggesting low adherence to these recommendations in UK adults aged $\geq 65$ years.

The mean HEI-2015 score was 59.9 (11.3) out of 100 (59.9\%), with component scores of $\geq 3.5$ out of 5 or $\geq 7$ out of 10 for total protein, refined grains, sodium and added sugars, and $\leq 1.5$ out of 5 or $\leq 3$ out of 10 for wholegrains, fatty acids and SFA (Figure 2). For whole fruit, total protein and refined grains, $\geq 50 \%$ of subjects scored maximum points, yet for wholegrains, fatty acids and SFA only $\leq 10 \%$ of subjects scored maximum points. 
362

363

10 for trans fatty acids, and of $\leq 3$ out of 10 for the wholegrains and nuts and legumes components (Figure 3). Proportions of subjects scoring maximum points was $\leq 10 \%$ for vegetables, fruit, wholegrains, nuts and legumes, red and processed meat and PUFA.

Full details of mean component scores and proportions meeting recommendations for each component are in Supplemental Table 2.

Associations between DQI-65s, HEI-2015 and AHEI-2010 scores and nutrient intake

As per Table 3, higher FDQI-65+PA, NFDQI-65 and NFDQI-65+PA scores were significantly associated with increased odds of meeting recommendations for almost all nutrients, except carbohydrates, MUFA, PUFA, sodium and alcohol for the FDQI-65+PA and MUFA and PUFA for the NFDQI-65+PA. In contrast, HEI-2015 and AHEI-2010 scores were not associated with increased odds of meeting our previously proposed nutritional recommendations ${ }^{(27)}$ for several nutrients of age-specific importance including calcium, vitamin D, vitamin B12 and alcohol (for the HEI-2015), and calcium, zinc, vitamin D, folate, vitamin B12, vitamin B6 and alcohol (for the AHEI-2010).

\section{Associations between DQI scores and biomarkers of nutrient intake}

DQI-65s, HEI-2015 and AHEI-2010 scores were significantly positively associated with nutritional intake biomarkers of relevance among older adults, particularly serum vitamin B12 and plasma $25(\mathrm{OH}) \mathrm{D}$, when adjusted for age and sex only, but not with haemoglobin concentration (Supplemental Table 3). After adjustment for all covariates, including supplement use and socioeconomic factors (model 3), the associations between DQI-65s and 
serum vitamin B12 became non-significant (Table 4) and AHEI-2010 scores became significantly inversely associated with haemoglobin concentration. Results for all models are in Supplemental Table 4.

\section{Associations between DQI scores and health markers}

When adjusting for age and sex only, DQI-65s, HEI-2015 and AHEI-2010 scores were all significantly inversely associated with anthropometric measures (BMI and WC), medication use, fasting TG, CRP, and odds of being classified with metabolic syndrome (except for NFDQI-65 and NFDQI-65+PA). They were also significantly positively associated with odds of good self-assessed health (Supplemental Table 4). Differential associations existed with other cardiometabolic risk factors (i.e., cholesterol markers and BP), with higher FDQI65+PA scores being significantly associated with higher TC and HDL-C, and higher NFDQI65 and NFDQI-65+PA scores being significantly associated with lower DBP.

After adjustment for age, sex, BMI and WC (where appropriate), smoking, and relevant medications (model 2), associations between FDQI-65+PA scores and TC were attenuated to become non-significant, as were associations between NFDQI-65, NFDQI65+PA and AHEI-2010 and both TG and metabolic syndrome classification, and NFDQI-65 and odds of good self-assessed health. All other previously observed associations remained significant in model 2.

After full adjustment, several of the associations were further attenuated to become non-significant. However, significant inverse associations remained between all DQIs and BMI, WC (except AHEI-2010 and FDQI-65+), medication use and CRP (Table 5). Moreover, higher FDQI-65 scores remained significantly associated with lower odds of being classified with metabolic syndrome and higher odds of good self-assessed health, and higher 
NFDQI-65+PA and NFDQI-65 scores remained associated with lower DBP. Finally, higher HEI-2015 scores remained significantly associated with higher odds of good self-assessed health. AHEI-2010 scores did not remain associated with any other outcomes.

\section{Discussion}

This study developed three variations of the DQI-65, which were tailored to nutritional and, in the case of FDQI-65+PA and NFDQI-65+PA, physical activity recommendations for UK older adults aged $\geq 65$ years. Unique aspects of the DQI-65s were the positive appraisal of protein, inclusion of physical activity (FBDQI-65+PA/NFBDQI$65+\mathrm{PA})$ and fluid, and the negative appraisal of alcohol. The DQI-65 variations differed in component assessment method, with the FBDQI-65+PA using a food-based approach, such as portions/day of sugary foods, number of alcoholic drinks and ratio of unsaturated fat rich oils and spreads to those containing primarily SFA. In contrast, the NFBDQI-65+PA and NFBDQI-65 assessed these components using a nutrient-based approach, such as mg/day, alcohol units and \% of total energy intake. These variations were created to assess the optimum composition of a DQI for this age group through evaluating the impact of selecting food groups (such as portions/day of sugary foods, number of alcoholic drinks), which would more easily translate into dietary and lifestyle advice) vs food groups and nutrients (such as sugar as \% of total energy, alcohol units), and of the inclusion of physical activity on associations with the index.

All three of the DQI-65 scores were associated with increased odds of meeting almost all of our previously proposed nutritional recommendations ${ }^{(27)}$ when using UK population nutritional intake data for those aged $\geq 65$ years. This demonstrates the DQI-65s, as composite indexes, effectively represent individual age-specific nutritional recommendations upon 
which they were developed. This was particularly the case for certain nutrients of importance among older adults such as protein, calcium, vitamin D and zinc, for which the DQI-65s demonstrated greater association with adherence to recommendations of these nutrients (based on larger magnitude of effect) relative to the HEI-2015 and AHEI-2010. Since the nutritional recommendations assessed against were also used to develop the DQS-65s, these findings may be considered biased. However, it seems prudent that any DQI to be used within this age group (whether this be the novel DQI-65s or existing HEI-2015/AHEI-2010) should predict adherence to these evidence-based recommendations.

In contrast to the NFDQI-65 and NFDQI-65+PA, higher FBDQI-65+PA scores were associated with a lower likelihood of meeting recommendations for alcohol intake. This was surprising as all scores assessed units of alcohol, whether directly or via numbers of drinks. It may be that those with higher alcohol intakes also had greater diet quality when considering other components (e.g. lower intakes of salty or sugary foods, higher intakes of vegetables) resulting in this unexpected association. Furthermore, there was a lack of association between FBDQI-65+PA scores and sodium intake. This may be due to the assessment of portions/day of salty foods rather than absolute sodium intakes (as per the NFDQI-65/NFDQI-65+PA). It is likely that sodium intake was underestimated in the FBDQI-65+PA as only key sources of sodium were included in the 'salty foods' classification. Therefore, component choices (food vs. nutrition based) and scoring methods are important in DQI design, with current findings suggesting the NFDQI-65 and NFDQI-65+PA may be superior to the FBDQI-65+PA when assessing nutritional intake in relation to evidence-based requirements.

Similarly, results suggest that the NFDQI-65 and NFDQI-65+PA may be more suited to assessing the dietary quality of UK older adults in relation to adequacy of nutritional intake than the HEI-2015 and AHEI-2010. For example, the HEI-2015 showed weaker associations with calcium and vitamin A intake than the DQI-65s, which could be attributed to the 
quantification method for dairy, a rich source of these nutrients, where the HEI-2015 sums total dairy irrespective of type (including fortified soy products), yet the DQI-65s account for typical portion sizes of milk, yoghurt and cheese, which vary in their nutritional profiles. As calcium intake is key in preserving bone health ${ }^{(27)}$, this approach may enhance predictive ability for musculoskeletal outcomes, although this would need confirmation using markers of bone health. Moreover, neither the HEI-2015 nor AHEI-2010 were associated with odds of meeting vitamin B12 recommendations, deficiency in which is prevalent among older adults due to impaired absorption with aging and poor intake of vitamin B12-rich foods ${ }^{(55)}$. Dairy and other animal products are also good sources of vitamin B12, therefore the higher weighting towards animal products in the DQI-65s may have contributed to the positive association with odds of meeting vitamin B12 recommendations, supporting its use to assess nutritional quality in an older population. Due to the HEI-2015 and AHEI-2010 being developed for a US rather than UK population, and based on the DQI-65 closely reflecting the proposed nutritional recommendations against which they were tested, greater suitability of the DQI-65s may be unsurprising. Further investigation is required to confirm this conclusion.

The DQI-65s, HEI-2015 and AHEI-2010 were all associated with various markers of cardiometabolic risk. For example, NFDQI-65 and NFDQI-65+PA (but not FDQI-65+PA, HEI-2015 and AHEI-2010) scores were inversely associated with DBP, and high BP is considered the leading risk factor for morbidity and mortality globally ${ }^{(56)}$, particularly relating to $\mathrm{CVD}^{(57)}$. Sodium intake has been positively associated with DBP in older adults ${ }^{(58)}$, therefore lack of association between DBP and the FDQI-65+PA may result from differential assessment of sodium intake as previously discussed.

Higher DQI-65 scores were associated with lower medication use, and the FDQI65+PA with better self-assessed health, like the HEI-2015. This suggests potential value of 
these indexes in predicting quality of life measures in an older population. The NFDQI65+PA, NFDQI-65 and HEI-2015 were also associated with lower WC, yet the FDQI-65 was not. Higher WC is considered an independent risk factor for mortality ${ }^{(59)}$, a key indicator of insulin resistance and overall cardiometabolic health ${ }^{(60)}$, and has been inversely associated with grip strength ${ }^{(61)}$, which is a component of Fried's frailty phenotype ${ }^{(19)}$. Finally, significant negative associations were also observed between CRP and all five DQIs. Like WC, higher CRP is associated with lower grip strength ${ }^{(62)}$ and increased disability risk ${ }^{(63)}$.

When comparing the nutrient and food based DQI-65s with and without physical activity, the magnitude of effect for associations between the NFDQI-65+PA and both CRP and number of medications were higher than for the NFDQI-65, whereas this was lower for associations with DBP. Few other differences existed in the present analysis with overall associations between the two nutrient and food-based DQI-65s (with/without physical activity) and nutrient, biochemical and health variables similar in both significance and magnitude of effect. Therefore, without statistical comparison between indexes it cannot be concluded whether including a physical activity component in the DQI-65s impacts associations and requires further investigation. In contrast, the nutrient and food-based DQI65s may potentially be superior to the food-based DQI-65 due to marginally greater associations with adherence to nutritional recommendations and some important health markers (e.g., BMI, WC and DBP). However, associations with health markers are limited by the methodology of the statistical analysis. Specifically, the cross-sectional NDNS data results in potential for reverse causality where dietary change has occurred following chronic disease diagnosis or identification of risk factors (e.g., high BP or TC), or where functional decline affects food accessibiliy, meal preparation and impairs food choice. This affects validity of associations, prevents cause and effect from being established, and limits conclusions regarding both the predictive and comparative value of individual DQIs. In addition, 4-day 
diet diaries may not reflect habitual diet, especially for components with weekly recommendations (e.g., oily fish and alcohol), and bias may exist in dietary records, therefore it is possible that subject misclassification exists. Consequently, prospective cohort studies using dietary assessment methods that capture longer term habitual diet (such as food frequency questionnaires) would help explore associations with clinical events, morbidity and mortality to determine the value of the novel DQI-65 in assessing dietary quality in relation to health outcomes. This is a future aim to scientifically validate the DQI-65.

This study's strengths include the development of three DQI-65 variations and comparison with validated and widely-used indexes. Moreover, despite high non-response rates in the NDNS for biological risk factors, applying sample weights reduced risk of selection and non-response bias ${ }^{(52)}$, and facilitated validation within a representative sample of UK older adults. However, some limitations exist. Development of the DQI-65s required subjectivity and, although decisions were justified by current research, different components and scoring methods may alter associations. For example, assumptions were made in equally weighting components (in line with approaches used by HEI-2015 and AHEI-2010) due to absence of qualitative evidence to support a different approach and the aim of targeting a range of markers of diet quality and health. Also, factor analysis was not performed to ensure that all included components relate to a single underlying dimension. Protein recommendations of $1.2 \mathrm{~g} / \mathrm{kg} / \mathrm{day}$ may also be insufficient for those who undertake high levels of physical activity which would not be captured in the index. Moreover, maximum DQI-65 scores were only obtainable if both dairy and oily fish were consumed as some consider the anabolic potential of animal protein in older adults higher than plant protein ${ }^{(64)}$, however applicability to vegetarian or vegan groups is limited. Further investigation is required to justify these decisions. Some measures of nutrient status (e.g., haemoglobin) may not directly reflect dietary intake due to physical adaptation to low status increasing bioavailability, 
532 affecting interpretation of results. Sodium content of water, which can be significant, was not

533 fully quantified in NDNS data, and may have impacted assessment of sodium intake.

534 Furthermore, less than $10 \%$ of individuals met many of our nutritional recommendations and

535 criteria for health marker variables, so the commonly used odds ratio ${ }^{(18,65)}$ may not be the

536 optimal measure, and multiple testing was not formally accounted for as analyses were treated

537 independently. Although a more conservative P-value for statistical significance was used,

$538<0.01$, the potential for false positive results still cannot be excluded. Finally, linearity across

539 the DQI score range has been assumed. This is unlikely to be the case in all score categories,

540 however this approach is used widely in DQI analyses ${ }^{(17,26)}$. Nonetheless, scope for further

541 investigations exist, including scientific assessment of the validity and reliability of the DQI.

In conclusion, three variations of a novel DQI-65 were developed that effectively

assess adherence to our previously proposed evidence-based age-specific nutritional

recommendations for UK adults aged $\geq 65$ years, potentially to a greater degree than existing

indexes tested. In addition, this cross-sectional analysis found the DQI-65s, HEI-2015 and

546 AHEI-2010 to be associated with a range of important health markers related to morbidity and mortality within a UK representative sample of adults aged $\geq 65$ years, although suggest the DQI-65s may be valuable tools for assessing diet quality in older adults in the UK, particularly when aiming to evaluate nutrient intake, and could support delivery of 551 tailored nutritional advice. It is possible that the nutrient and food-based DQI-65s (NFDQI65/NFDQI-65+PA) may be superior to the food-based DQI-65 (FDQI-65+PA), however the added benefit of including physical activity within the index is uncertain. Assessment of the DQI-65s predictability in relation to clinical and health outcomes was limited, yet these 
study data, including clinical outcomes and mortality, with further comparisons against existsing indexes to support DQI-65 validation.

\section{Sources of support: No support}

Conflicts of interest: No conflicts of interests. JAL sits on the UK Government's Scientific Advisory Committee for Nutrition (SACN). This paper reflects independent research.

Author contributions: ND, RF, MW and JAL designed research; ND conducted research; ND analysed data; DH assisted in calculation of diet quality scores; ND drafted the paper. All authors read and approved the final manuscript.

Supplemental Methods, Supplemental Table 1-5 and Supplemental References are available from the "Supplementary data" link in the online posting of the article and from the same link in the online table of contents at https://academic.oup.com/jn/. 


\section{References}

1. World Health Organisation (2018) Ageing and health. https://www.who.int/news-room/factsheets/detail/ageing-and-health (accessed 20th August 2019).

2. Government Office for Science (2016) Future of an ageing population. https://assets.publishing.service.gov.uk/government/uploads/system/uploads/attachment_dat a/file/816458/future-of-an-ageing-population.pdf (accessed 20 ${ }^{\text {th }}$ August 2019).

3. Jong JCK, Mathers JC \& Franco OH (2014) Nutrition and healthy ageing: the key ingredients. Proc Nutr Soc 73(2), 249-59.

4. MacDonell SO, Miller JC, Waters DL et al. (2016) Dietary patterns in the frail elderly. Curr Nutr Rep 73(2), 68-75.

5. Franco RZ, Fallaize R, Hwang F et al. (2019) Strategies for online personalised nutrition advice employed in the development of the eNutri web app. Proc Nutr Soc 78, 407-417.

6. de Haas SCM, de Jonge EAL, Voortman T et al. (2018) Dietary patterns and changes in frailty status: the Rotterdam study. Eur J Nutr 57(7), 2365-2375.

7. Harnack L, Nicodemus K, Jacobs DR, Jr. et al. (2002) An evaluation of the Dietary Guidelines for Americans in relation to cancer occurrence. Am J Clin Nutr 76(4), 889-896.

8. Knoops KTB, de Groot LCPGM, Kromhout D, Perrin A-E et al. (2004) Mediterranean diet, lifestyle factors, and 10-year mortality in elderly European men and women: The HALE project. JAMA 292(12), 1433-1439.

9. Kourlaba G, Polychronopoulos E, Zampelas A et al. (2009) Development of a diet index for older adults and its relation to cardiovascular disease risk factors: The Elderly Dietary Index. J Am Diet Assoc 109(6), 1022-1030.

10. Lasheras C, Fernandez S \& Patterson AM (2000) Mediterranean diet and age with respect to overall survival in institutionalized, nonsmoking elderly people. Am J Clin Nutr 71(4), 987992. 
11. Milaneschi Y, Bandinelli S, Corsi AM et al. (2011) Mediterranean diet and mobility decline in older persons. Exper Gerontol 46(4), 303-8.

12. Newby PK, Hu FB, Rimm EB et al. (2003) Reproducibility and validity of the Diet Quality Index Revised as assessed by use of a food-frequency questionnaire. Am J Clin Nutr 78(5), 941-949.

13. Osler M \& Schroll M (1997) Diet and mortality in a cohort of elderly people in a north European community. Int J Epidemiol 26(1), 155-159.

14. Seymour JD, Calle EE, Flagg EW et al. (2003) Diet Quality Index as a predictor of shortterm mortality in the American Cancer Society Cancer Prevention Study II Nutrition Cohort. Am J Epidemiol 157(11), 980-988.

15. Talegawkar SA, Bandinelli S, Bandeen-Roche K et al. (2012) A higher adherence to a Mediterranean-style diet is inversely associated with the development of frailty in community-dwelling elderly men and women. J Nutr 142(12), 2161-2166.

16. Trichopoulou A, Kourisblazos A, Wahlqvist ML et al. (1995) Diet and overall survival in elderly people. BMJ 311(7018), 1457-1460.

17. Xu B, Houston DK, Locher JL et al. (2012) Higher healthy eating index-2005 scores are associated with better physical performance. J Gerontol A Biol Sci Med Sci 67(1), 93-99.

18. Xu B, Houston D, Locher JL et al. (2012) The association between Healthy Eating Index2005 scores and disability among older Americans. Age Ageing 41(3), 365-371.

19. Fried LP, Tangen CM, Walston J et al. (2001) Frailty in older adults: evidence for a phenotype. J Gerontol A Biol Sci Med Sci 56(3), M146-156.

20. Kim J \& Lee Y (2011) Frequency of dairy consumption and functional disability in older persons. J Nutr Health Aging 15(9), 795-800.

21. Aune D, Giovannucci E, Boffetta P et al. (2017) Fruit and vegetable intake and the risk of cardiovascular disease, total cancer and all-cause mortality-a systematic review and doseresponse meta-analysis of prospective studies. Int J Epidemiol 46(3), 1029-1056. 
22. Deghan M, Mente A, Rangarajan S (2018) Association of dairy intake with cardiovascular disease and mortality in 21 countries from five continents (PURE): A prospective cohort study. The Lancet 392(10161), P2288-2297.

23. De Spiegeleer A, Petrovic M, Boeckxstaens P et al. (2016) Treating sarcopenia in clinical practice: where are we now? Acta Clin Belg 71(4), 197-205.

24. Bollwein J, Diekmann R, Kaiser MJ et al. (2013) Dietary quality is related to frailty in community-dwelling older adults. J Gerontol A Biol Sci Med Sci 68(4), 483-489.

25. Scientific Advisory Committee on Nutrition (2004) Advice on fish consumption: Benefits \& risks. London, UK: TSO.

26. Chiuve SE, Fung TT, Rimm EB et al. (2012) Alternative dietary indices both strongly predict risk of chronic disease. J Nutr 142(6), 1009-1018.

27. Dorrington N, Fallaize R, Hobbs DA, Weech M, Lovegrove JA (2020) A review of nutritional requirements of adults aged $\geq 65 \mathrm{y}$ in the UK. $J$ Nutr 150(9), 2245-2256.

28. Breen L \& Phillips SM (2011) Skeletal muscle protein metabolism in the elderly: Interventions to counteract the 'anabolic resistance' of ageing. Nutr Metab 8, 68.

29. Waijers P, Feskens EJM \& Ocke MC (2007) A critical review of predefined diet quality scores. Br J Nutr 97(2), 219-231.

30. Department of Health (2011) Physical activity guidelines for older adults (65+ years). https://www.gov.uk/government/uploads/system/uploads/attachment_data/file/213741/dh_1 28146.pdf (accessed 21st September 2017).

31. Public Health England (2016) The Eatwell guide. Helping you eat a healthy, balanced diet. https://assets.publishing.service.gov.uk/government/uploads/system/uploads/attachment_dat a/file/551502/Eatwell_Guide_booklet.pdf (accessed 20th September 2017).

32. Koopman R, Van Loon LJC. Aging, exercise and muscle protein metabolism. J Appl Physiol 2009;106(6):2040-2048.

33. Hunter DJ, Sambrook PN. Bone loss: Epidemiology of bone loss. Arthritis Res 2000;2(6):441-445. 
34. Aune D, Giovannucci E, Boffetta P et al. (2017) Fruit and vegetable intake and the risk of cardiovascular disease, total cancer and all-cause mortality-a systematic review and doseresponse meta-analysis of prospective studies. Int J Epidemiol 46(3), 1029-1056.

35. Li Y, Hruby A, Bernstein AM et al. (2015) Saturated fat as compared with unsaturated fats and sources of carbohydrates in relation to risk of coronary heart disease: A prospective cohort study. J Am Coll Cardiol 66(14), 1538-1548.

36. Scientific Advisory Committee on Nutrition (2003) Salt and health. London, UK: TSO.

37. Alam S, Purdie DM, Johnson AG (1999) Evaluation of the potential interaction between $\mathrm{NaCl}$ and prostaglandin inhibition in elderly individuals with isolated systolic hypertension. J Hypertens 17(8), 1195-202.

38. Truswell AS (2009) Dietary guidance for older Australians. Nutr Diet 66(4), 243-248.

39. El-Sharkawy AM, Sahota O, Lobo DN (2015) Acute and chronic effects of hydration status on Health. Nutr Rev 73(Suppl 2), 97-109.

40. Bernstein M \& Munoz N (2012) Position of the Academy of Nutrition and Dietetics: Food and nutrition for older adults: Promoting health and wellness. J Academy of Nutrition and Dietetics 112(8), 1255-1277.

41. British Dietetic Association (2016) Food fact sheet: Portion sizes. https://www.bda.uk.com/foodfacts/portionsizesfoodfactsheet.pdf (accessed 1st November 2017).

42. Drink Aware (n.d.) Alcohol limits and unit guidelines. https://www.drinkaware.co.uk/alcohol-facts/alcoholic-drinks-units/alcohol-limits-unitguidelines/ (accessed $1^{\text {st }}$ November 2017).

43. Scientific Advisory Committee on Nutrition (2010) Iron and health. London, UK: TSO.

44. Mindell J (2008) National Diet and Nutrition Survey. Results from Years 1-4 (combined) of the Rolling Programme (2008/2009-2011/2012). Appendix V. Measuring physical activity in adults using the Recent Physical Activity Questionnaire (RPAQ). London, UK: Public Health England. Available at: https://www.gov.uk/government/statistics/national-diet-and- 
nutrition-survey-results-from-years-1-to-4-combined-of-the-rolling-programme-for-2008and-2009-to-2011-and-2012.

45. Tieland M, Beelan J, Laan ACM, Poon S, de Groot LCPGM, Seeman E, Wang X, Iuliano S (2017) An even distribution of protein intake daily promotes protein adequacy but does not influence nutritional status in institutionalized elderly. J Am Med Dir Assoc 19(1), 33-39.

46. Krebs-Smith SM, Pannucci TE, Subar AF, Kirkpatrick SI, Lerman JL, Tooze JA, Wilson MM, Reedy J (2018) Update of the Healthy Eating Index: HEI-2015. J Acad Nutr Diet 118(9), 1591-1602.

47. NatCen Social Research, MRC Elsie Widdowson Laboratory, UCL Medical School (2015) National Diet and Nutrition Survey Years 1-6, 20008/09-2013/14.[data collection]. $7^{\text {th }}$ Edition. UK Data Service. SN:6533. doi: 10.5255.UKDA-SN-6533-7 (accessed $8^{\text {th }}$ November 2017).

48. Public Health England (2014) National Diet and Nutrition Survey. Results from Years 1, 2, 3 and 4 (combined) of the Rolling Programme (2008/2009 - 2011/2012). London, UK: Public Health England.

49. Fallaize R, Forster H, Macready AL, Walsh MC, Mathers JC, Brennan L, Gibney ER, Gibney MJ, Lovegrove JA (2014) Online dietary intake estimation: Reproducibility and validity of the Food4Me food frequency questionnaire against a 4-day weighed food record. J Med Internet Res 1(8): e190.

50. Public Health England (2014) McCance and Widdowson's The Composition of Foods. 7th Summary Edition. Cambridge, UK: Royal Society of Chemistry.

51. Food Standards Agency (2002) McCance and Widdowson's The Composition of Foods. 6th Summary Edition. Cambridge, UK: Royal Society of Chemistry.

52. Tipping S (2014) National Diet and Nutrition Survey. Results from Years 1-4 (combined) of the Rolling Programme (2008/2009-2011/2012). Appendix B. Weighting the National Diet and Nutrition Survey Rolling Programme sample. London, UK: Public Health England. Available at: https://www.gov.uk/government/statistics/national-diet-and-nutrition-survey- 
results-from-years-1-to-4-combined-of-the-rolling-programme-for-2008-and-2009-to-2011and-2012.

53. Expert Panel on Detection, Evaluation and Treatment of High Blood Cholesterol in Adults (2001) Executive summary of the third report of the National Cholesterol Education Program (NCEP) Expert Panel on Detection, Evaluation, and Treatment of High Blood Cholesterol in Adults (Adult Treatment Panel III). JAMA 285(19), 2486-2497.

54. Public Health England (2018) Appendix AA. Calculation of free sugars and AOAC fibre in the NDNS RP. London, UK: Public Health England. Available at: https://www.gov.uk/government/statistics/national-diet-and-nutrition-survey-results-fromyears-1-to-4-combined-of-the-rolling-programme-for-2008-and-2009-to-2011-and-2012.

55. Fernández-Barrés S, Martín N, Canela T, García-Barco M, Basora J, Arija V (2016) Dietary intake in the dependent elderly: Evaluation of the risk of nutritional deficit. J Human Nutr Diet 29(2), 174-184.

56. Forouzanfar MH, Afshin A, Alexander LT et al. (2016) Global, regional and national comparative risk assessment of 79 behavioural, environmental and occupational, and metabolic risks or clusters of risks, 1990-2015: a systematic analysis for the Global Burden of Disease Study 2015. Lancet 388(10053), 1659-1724.

57. Forouzanfar MH, Liu P, Roth GA et al. (2017) Global burden of hypertension and systolic blood pressure of at least 110 to $115 \mathrm{~mm} \mathrm{Hg}, 1990-2015$. JAMA 317(2), 165-182.

58. Alam S, Purdie DM, Johnson AG (1999). Evaluation of the potential interaction between $\mathrm{NaCl}$ and prostaglandin inhibition in elderly individuals with isolated systolic hypertension. J Hypertens 17(8), 1195-1202.

59. Cerhan JR, Moore SC, Jacobs EJ et al. (2014) A pooled analysis of waist circumference and mortality in 650,000 adults. Mayo Clin Proc 89(3), 335-345.

60. Després J-P, Lemieux I, Bergeron J et al. (2008) Abdominal obesity and the metabolic syndrome: contribution to global cardiometabolic risk. Arterioscler Thromb Vasc Biol 28(6), 1039-1049. 
61. Keevil VL, Luben R, Dalzell N et al. (2015) Cross-sectional associations between different measures of obesity and muscle strength in men and women in a British cohort study. $J$ Nutr Health Aging 19(1), 3-11.

62. Hamer M \& Molloy GJ (2009) Association of C-reactive protein and muscle strength in the English Longitudinal Study of Ageing. Age 31(3), 171-177.

63. Legrand D, Vaes B, Mathei C et al. (2014) Muscle strength and physical performance as predictors of mortality, hospitalization, and disability in the oldest old. J Am Geriatr Soc 62(6), 1030-1038.

64. Gorissen SHM \& Witard OC (2018) Characterising the muscle anabolic potential of dairy, meat and plant-based protein sources in older adults. Proc Nutr Soc 77(1), 20-31.

65. Huijbregts P, Fekens E, Räsänen L et al. (1998) Dietary patterns and cognitive function in elderly men in Finland, Italy and the Netherlands. Eur J Clin Nutr 52, 826-831. 
Table 1. Components and scoring method of DQI-65 variations ${ }^{l}$.

\begin{tabular}{|c|c|c|c|c|}
\hline Component & Recommendation & $\begin{array}{l}\text { Criteria for minimum } \\
\text { score (0 points) }\end{array}$ & $\begin{array}{c}\text { Criteria for } \\
\text { maximum score }\end{array}$ & $\begin{array}{c}\text { Maximum } \\
\text { score }\end{array}$ \\
\hline \multicolumn{5}{|l|}{ FDQI-65+PA } \\
\hline Vegetables ${ }^{2,3}$ & $\geq 3$ portions/day & 0 portions/day & $\geq 3$ portions/day & 10 \\
\hline Fruit $^{2,4}$ & $\geq 2$ portions/day & 0 portions/day & $\geq 2$ portions/day & 10 \\
\hline Protein $^{5}$ & $\geq 3$ portions/day & 0 portions/day & $\geq 3$ portions/day & 10 \\
\hline Oily fish ${ }^{6}$ & $\geq 1$ portion/week & 0 portions/day & $\geq 1$ portion/week & 10 \\
\hline Low fat dairy ${ }^{7}$ & $\geq 3$ portions/day & 0 portions/day & $\geq 3$ portions/day & 10 \\
\hline $\begin{array}{l}\text { Wholegrain } \\
\text { carbohydrates }\end{array}$ & $\geq 3$ portions/day & 0 portions/day & $\geq 3$ portions/day & 10 \\
\hline Free sugars ${ }^{9,10}$ & $\leq 1$ portion/day & $>2$ portions/day & $\leq 1$ portion/day & 10 \\
\hline Sodium 9,11 & $\leq 1$ portion/day & $>2$ portions/day & $\leq 1$ portion/day & 10 \\
\hline Fat and fatty acids ${ }^{9,12}$ & $100 \%$ unsaturated & $0 \%$ unsaturated & $100 \%$ unsaturated & 10 \\
\hline Fluid $^{9,13}$ & $\geq 6$ portions/day & 0 portions/day & $\geq 6$ portions/day & 10 \\
\hline Alcohol $^{9,14}$ & $\leq 14$ units/week & $>14$ units/week & 0 units/week & 10 \\
\hline \multirow[t]{2}{*}{ Physical activity ${ }^{15}$} & $\begin{array}{l}\geq 20 \text { minutes/day } \\
\text { moderate activity }\end{array}$ & 0 minutes/day & $\geq 20$ minutes/day & 10 \\
\hline & & & Maximum Total Score & 120 \\
\hline
\end{tabular}

NFDQI-65+PA (and NFDQI-65)

Vegetables ${ }^{2,3}$

Fruit $^{2,4}$

Protein $^{5}$

Oily fish ${ }^{6}$

Low fat dairy ${ }^{7}$

Wholegrain

carbohydrates $^{2,8}$

$$
\geq 3 \text { portions/day }
$$

$\geq 2$ portions/day

$\geq 3$ portions/day

$\geq 1$ portion/week

$\geq 3$ portions/day

$\geq 3$ portions/day
0 portions/day

0 portions/day

0 portions/day

0 portions/day

0 portions/day

0 portions/day $\geq 3$ portions/day

$\geq 2$ portions/day

10

10

$\geq 3$ portions/day

$\geq 1$ portion/week

10

$\geq 3$ portions/day

10

10 


\begin{tabular}{lc}
\hline Free sugars & $\leq 5 \%$ energy intake \\
Sodium $^{9,17}$ & $\leq 2400 \mathrm{mg} /$ day \\
Fat and fatty acids $^{18}$ & \\
Ratio of PUFA+MUFA $_{\text {to } \text { SFA }^{9,19}}$ & (PUFA+MUFA)/SFA $\geq 2$ \\
SFA $^{9}$ & $\leq 10 \%$ energy intake \\
Fluid $^{9,13}$ & $\geq 6$ portions/day \\
Alcohol $^{9,20}$ & $\leq 14$ units/week \\
Physical activity & $\geq 20$ minutes/day \\
& moderate activity
\end{tabular}

$>10 \%$ energy intake

$\leq 5 \%$ energy intake

10

$>3200$ mg/day

$\leq 2400 \mathrm{mg} /$ day

10
$\underset{<1}{(\mathrm{PUFA}+\mathrm{MUFA}) / \mathrm{SFA}}$

$>20 \%$ energy intake

0 portions/day

$>14$ units/week

0 minutes/day

\author{
(PUFA+MUFA)/SFA \\ $\geq 2$
}

$\leq 10 \%$ energy intake

$\geq 6$ portions/day

0 units/week

$\geq 20$ minutes/day

\footnotetext{
$1 \%$ energy intake refers to total energy; BMI, body mass index; DQI-65, diet quality index for older adults; FDQI-65+PA, Food-based Diet Quality Index for older adults with physical activity; MUFA, monounsaturated fatty acids; NDNS, National Diet and Nutrition Survey; NFDQI-65, Nutrient and Food-based Diet Quality Index for older adults; NFDQI-65+PA, Nutrient and Food-based Diet Quality Index for older adults with physical activity; PUFA, polyunsaturated fatty acids; SFA, saturated fatty acids; SACN, Scientific Advisory Committee for Nutrition.

${ }^{2}$ Quantification based on the UK Eatwell Guide recommendations ${ }^{(31)}$.

${ }^{3}$ Portion sizes based on standard portions ${ }^{(31)}: 80 \mathrm{~g}$ vegetables or legumes, $15 \mathrm{~g}$ tomato puree; only up to 1 portion of legumes and 1 portion of tomato puree allowed.

${ }^{4}$ Portion sizes based on standard portions ${ }^{(31)}: 80 \mathrm{~g}$ fruit, $150 \mathrm{~mL}$ fruit juice, $30 \mathrm{~g}$ dried fruit; only up to 1 portion of dried fruit or fruit juice allowed.

5 Represents food group from the UK Eatwell Guide ${ }^{(31)}$; based on portions required to meet our previously proposed protein recommendations ${ }^{(27)}$; standard portion sizes used ${ }^{(41)}: 70 \mathrm{~g}$ red meat, $100 \mathrm{~g}$ poultry, $140 \mathrm{~g}$ fish or shellfish, approximately $120 \mathrm{~g}$ or $2 \mathrm{eggs}$, $150 \mathrm{~g}$ legumes, $30 \mathrm{~g}$ nuts, $250 \mathrm{~mL}$ milk, $30 \mathrm{~g}$ cheese, $125 \mathrm{~g}$ yoghurt, $100 \mathrm{~g}$ meat alternatives; only up to 1 portion of red meat (not processed meat), 1 portion of legumes or nuts and 1 portion of dairy or alternatives allowed per day.

${ }^{6}$ Quantification and portion size based on SACN advice ${ }^{(25)}$; portion size $140 \mathrm{~g}$ cooked fish.

7 Represents food group from the UK Eatwell Guide ${ }^{(31)}$; quantification based on portions required to meet proposed calcium recommendations; low fat milk, low fat yoghurt, reduced fat or low fat cheese only, no other dairy included nor dairy alternatives; high fat dairy if BMI $<18.5 \mathrm{~kg} / \mathrm{m}^{2}$; portion sizes based on standard portions ${ }^{(41)}: 250 \mathrm{~mL}$ milk, $30 \mathrm{~g}$ cheese, $125 \mathrm{~g}$ yoghurt; 1 portion of cheese allowed per day.

${ }^{8}$ Portion sizes based on standard portions ${ }^{(41)}$ : $190 \mathrm{~g}$ cooked pasta, rice or grains, $80 \mathrm{~g}$ bread or crackerbreads, $30 \mathrm{~g}$ breakfast cereals or flour. ${ }^{9}$ Quantification based on our previously proposed nutritional recommendations ${ }^{(27)}$.

${ }^{10}$ Foods chosen are main contributors to free sugar intake in NDNS; portion sizes based on average available portions: $40 \mathrm{~g}$ cakes, biscuits or cereal bars, $100 \mathrm{~g}$ buns, pastries, pancakes, dairy desserts and sponge puddings, $20 \mathrm{~g}$ confectionery or sweet preserves, $330 \mathrm{~mL}$ sugar sweetened beverages, $15 \mathrm{~g}$ sugar.

${ }^{11}$ Foods chosen are main contributors to sodium intake in NDNS; portion sizes based on average available portions or standard portion sizes $^{(43)}: 25 \mathrm{~g}$ salty savoury snacks, crisps or salted nuts, $70 \mathrm{~g}$ processed meat.

${ }^{12}$ Based on cooking oils and spreads; percentage of spreads and oils predominantly comprised of unsaturated fatty acids; unsaturated oils and spreads defined as having fat composition of (MUFA+PUFA)/SFA $\geq 2$; percentage calculated as proportion of MUFA/PUFA oils and spreads out of total oils and spreads; score of 5 assigned if no cooking oils or spreads used.

${ }^{13}$ Portion sizes based on the UK Eatwell Guide recommendations ${ }^{(31)}: 250 \mathrm{~mL}$; only up to $150 \mathrm{~mL}$ portion of fruit or vegetable juice allowed according to the UK Eatwell Guide ${ }^{(31)}$; not including alcohol or sugar sweetened beverages.

${ }^{14} 1$ portion equals 1 alcohol unit ${ }^{(42)}: 75 \mathrm{~mL}$ wine, $220 \mathrm{~mL}$ beer, lager, cider or alcoholic soft drinks, $25 \mathrm{~mL}$ spirits, liqueurs or fortified wine; not including low or no alcohol versions.

${ }^{15}$ Quantification based on UK physical activity guidelines ${ }^{(30)}$; includes walking, cycling, swimming, dancing, gardening, and other active leisure pursuits.

${ }^{16}$ Represented as \% total energy intake; based on non-milk extrinsic sugars where free sugars not available.

${ }^{17}$ No lower limit set as recommendation to increase sodium intake only justified based on diagnosis of low blood electrolytes; represented as mg/day; adjusted to account for underreporting in analysis based on average underreporting in NDNS sample compared to urinary sodium; adjusted score based on 10 points for $\leq 2000 \mathrm{mg} /$ day and 0 points for $\leq 2800 \mathrm{mg} /$ day.

${ }^{18}$ Component split into two parts

${ }^{19}$ Ratio determined by recommended relative \% contribution to energy intake for MUFA, PUFA and SFA.

${ }^{20}$ Represented as g/day; 1 unit is $8 \mathrm{~g}$ alcohol.

${ }^{21}$ Component not included in NFDQI-65.

${ }^{22}$ Total score for NFDQI-65 110 points.
} 
Table 2. Characteristics of study population from $\mathrm{UK} \mathrm{NDNS}^{l}$.

\begin{tabular}{|c|c|}
\hline Characteristic & Total $(n=871)$ \\
\hline Male (\%) & 44.2 \\
\hline Age (year) & $73.6 \pm 6.6$ \\
\hline \multicolumn{2}{|l|}{ Age group $(\%)$} \\
\hline 65-79 years & 80.1 \\
\hline$\geq 80$ years & 19.9 \\
\hline \multicolumn{2}{|l|}{ BMI category $(\%)$} \\
\hline Underweight $<18.5 \mathrm{~kg} / \mathrm{m}^{2}$ & 0.9 \\
\hline Healthy $18.5-24.99 \mathrm{~kg} / \mathrm{m}^{2}$ & 24.0 \\
\hline Overweight $25-29.9 \mathrm{~kg} / \mathrm{m}^{2}$ & 37.6 \\
\hline Obese $\geq 30 \mathrm{~kg} / \mathrm{m}^{2}$ & 24.9 \\
\hline Not available & 12.6 \\
\hline \multicolumn{2}{|l|}{ Ethnicity (\%) } \\
\hline White & 96.8 \\
\hline Mixed ethnic group & 0.8 \\
\hline Black or Black British & 0.7 \\
\hline Asian or Asian British & 0.9 \\
\hline Any other group & 0.9 \\
\hline \multicolumn{2}{|l|}{ Smoking (\%) } \\
\hline Current smoker & 9.8 \\
\hline Ex-regular smoker & 39.2 \\
\hline Never regular smoker & 51.0 \\
\hline \multicolumn{2}{|l|}{ Education $(\%)$} \\
\hline Degree or equivalent & 11.6 \\
\hline Higher education, below degree level & $\begin{array}{l}6.1 \\
68\end{array}$ \\
\hline GCE, A level, or equivalent & $\begin{array}{c}6.8 \\
158\end{array}$ \\
\hline GCSE A*-C or equivalent & $\begin{array}{c}15.8 \\
3.3\end{array}$ \\
\hline GCSE grades D-G, commercial qualifications or apprenticeship & 3.3 \\
\hline Foreign or other qualifications & 11.3 \\
\hline No qualifications & 44.0 \\
\hline Refused & 1.2 \\
\hline \multicolumn{2}{|l|}{ Income (\%) } \\
\hline$\leq £ 10,000$ & 4.4 \\
\hline$>£ 10,000-£ 20,000$ & 33.2 \\
\hline$>£ 20,000-£ 40,000$ & 29.8 \\
\hline$>£ 40,000$ & 10.8 \\
\hline Not available & 21.9 \\
\hline \multicolumn{2}{|l|}{ Marital status (\%) } \\
\hline Married & 58.7 \\
\hline Widowed & 21.0 \\
\hline Divorced & 3.1 \\
\hline Separated & 12.9 \\
\hline Never married & 4.3 \\
\hline \multicolumn{2}{|l|}{ Vegetarian (\%) } \\
\hline Vegetarian & 1.0 \\
\hline Vegan & 0.3 \\
\hline Neither & 98.7 \\
\hline Supplement use (\%) & 40.5 \\
\hline
\end{tabular}


${ }^{1}$ Values for continuous variables are $\bar{x} \pm S D$ and values for categorical variables are percentages of subjects within each category; NDNS interviewer weights applied; BMI, body mass index; NDNS, National Diet and Nutrition Survey. 
Table 3. Association between DQI-65 s, HEI-2015 and AHEI-2010 scores and odds of meeting nutritional recommendations for subjects aged $\geq 65 y$ from UK NDNS years $2-6(n=871)^{l}$

\begin{tabular}{|c|c|c|c|c|c|c|c|c|c|c|c|c|c|}
\hline \multirow[b]{2}{*}{ Nutrient } & \multirow[b]{2}{*}{ Recommendation $^{2}$} & \multirow[b]{2}{*}{ Mean (SD) } & \multirow{2}{*}{$\begin{array}{l}\text { Proportion } \\
\text { meeting } \\
\text { recommend } \\
\text { dations }(\%)\end{array}$} & \multicolumn{2}{|c|}{ FDQI-65+PA } & \multicolumn{2}{|c|}{ NFDQI-65+PA } & \multicolumn{2}{|c|}{ NFDQI-65 } & \multicolumn{2}{|c|}{ HEI-2015 } & \multicolumn{2}{|c|}{ AHEI-2010 } \\
\hline & & & & $\begin{array}{c}\text { OR }(95 \% \\
\text { CI) }\end{array}$ & $\begin{array}{c}\mathbf{P} \\
\text { value }\end{array}$ & $\begin{array}{l}\text { OR }(95 \% \\
\text { CI) }\end{array}$ & $\begin{array}{c}\mathbf{P} \\
\text { value }\end{array}$ & $\begin{array}{l}\text { OR (95\% } \\
\text { CI) }\end{array}$ & $\begin{array}{c}\mathbf{P} \\
\text { value }\end{array}$ & $\begin{array}{l}\text { OR }(95 \% \\
\text { CI) }\end{array}$ & $\begin{array}{c}P \\
\text { value }\end{array}$ & $\begin{array}{l}\text { OR }(95 \% \\
\text { CI) }\end{array}$ & $\begin{array}{c}\mathbf{P} \\
\text { value }\end{array}$ \\
\hline Carbohydrate $^{3}$ & $50 \%$ total energy & $45.8(6.8)$ & 79.9 & $\begin{array}{c}1.00 \\
(0.95,1.06) \\
\end{array}$ & 0.969 & $\begin{array}{c}1.13 \\
(1.07,1.20) \\
\end{array}$ & $<0.001$ & $\begin{array}{c}1.16 \\
(1.10,1.23) \\
\end{array}$ & $<0.001$ & $\begin{array}{c}1.10 \\
(1.04,1.17) \\
\end{array}$ & 0.002 & $\begin{array}{c}1.05 \\
(0.98,1.14) \\
\end{array}$ & 0.193 \\
\hline Free sugars ${ }^{4}$ & $\leq 5 \%$ total energy & $11.0(5.6)$ & 13.8 & $\begin{array}{c}1.11 \\
(1.04,1.19) \\
\end{array}$ & 0.001 & $\begin{array}{c}1.26 \\
(1.18,1.36) \\
\end{array}$ & $<0.001$ & $\begin{array}{c}1.29 \\
(1.19,1.38) \\
\end{array}$ & $<0.001$ & $\begin{array}{c}1.11 \\
(1.03,1.19) \\
\end{array}$ & 0.006 & $\begin{array}{c}1.16 \\
(1.10,1.22) \\
\end{array}$ & $<0.001$ \\
\hline Protein $^{5}$ & $\begin{array}{c}\geq 1.2 \mathrm{~g} / \mathrm{kg} \text { body } \\
\text { weight } / \text { day }\end{array}$ & $1.0(0.3)$ & 18.8 & $\begin{array}{c}1.23 \\
(1.16,1.31) \\
\end{array}$ & $<0.001$ & $\begin{array}{c}1.30 \\
(1.22,1.40) \\
\end{array}$ & $<0.001$ & $\begin{array}{c}1.31 \\
(1.22,1.40)\end{array}$ & $<0.001$ & $\begin{array}{c}1.18 \\
(1.11,1.26)\end{array}$ & $<0.001$ & $\begin{array}{c}1.10 \\
(1.03,1.18) \\
\end{array}$ & 0.007 \\
\hline Fat & $\leq 33 \%$ total energy & 33.8 (5.9) & 44.8 & $\begin{array}{c}1.15 \\
(1.10,1.20) \\
\end{array}$ & $<0.001$ & $\begin{array}{c}1.23 \\
(1.17,1.29) \\
\end{array}$ & $<0.001$ & $\begin{array}{c}1.23 \\
(1.17,1.29) \\
\end{array}$ & $<0.001$ & $\begin{array}{c}1.47 \\
(1.39,1.56) \\
\end{array}$ & $<0.001$ & $\begin{array}{c}1.31 \\
(1.22,1.41) \\
\end{array}$ & $<0.001$ \\
\hline SFA & $\leq 10 \%$ total energy & $13.2(3.4)$ & 17.8 & $\begin{array}{c}1.18 \\
(1.11,1.25) \\
\end{array}$ & $<0.001$ & $\begin{array}{c}1.30 \\
(1.22,1.39) \\
\end{array}$ & $<0.001$ & $\begin{array}{c}1.31 \\
(1.22,1.40) \\
\end{array}$ & $<0.001$ & $\begin{array}{c}1.97 \\
(1.79,2.17) \\
\end{array}$ & $<0.001$ & $\begin{array}{c}0.85 \\
(0.80,0.90) \\
\end{array}$ & $<0.001$ \\
\hline $\begin{array}{l}\text { Trans fatty } \\
\text { acids }^{6}\end{array}$ & $\leq 2 \%$ total energy & $0.6(0.3)$ & 100 & - & - & - & - & - & - & - & - & - & - \\
\hline MUFA $^{3}$ & $12 \%$ total energy & $11.8(2.4)$ & 66.3 & $\begin{array}{c}0.91 \\
(0.87,0.95)\end{array}$ & $<0.001$ & $\begin{array}{c}0.91 \\
(0.87,0.96)\end{array}$ & $<0.001$ & $\begin{array}{c}0.90 \\
(0.86,0.95)\end{array}$ & $<0.001$ & $\begin{array}{c}0.85 \\
(0.81,0.90)\end{array}$ & $<0.001$ & $\begin{array}{c}0.85 \\
(0.80,0.90)\end{array}$ & $<0.001$ \\
\hline PUFA $^{3}$ & $6 \%$ total energy & $9.2(2.8)$ & 66.9 & $\begin{array}{c}0.90 \\
(0.86,0.95)\end{array}$ & $<0.001$ & $\begin{array}{c}0.87 \\
(0.83,0.92) \\
\end{array}$ & $<0.001$ & $\begin{array}{c}0.87 \\
(0.83,0.92) \\
\end{array}$ & $<0.001$ & $\begin{array}{c}0.84 \\
(0.80,0.89) \\
\end{array}$ & $<0.001$ & $\begin{array}{c}0.80 \\
(0.75,0.85) \\
\end{array}$ & $<0.001$ \\
\hline AOAC fibre $^{7}$ & $\geq 30 \mathrm{~g} /$ day & $18.5(6.5)$ & 5.9 & $\begin{array}{c}1.51 \\
(1.35,1.70) \\
\end{array}$ & $<0.001$ & $\begin{array}{c}1.32 \\
(1.18,1.46) \\
\end{array}$ & $<0.001$ & $\begin{array}{c}1.29 \\
(1.16,1.44) \\
\end{array}$ & $<0.001$ & $\begin{array}{c}1.34 \\
(1.20,1.49) \\
\end{array}$ & $<0.001$ & $\begin{array}{c}1.28 \\
(1.15,1.44) \\
\end{array}$ & $<0.001$ \\
\hline Calcium & $\geq 1000$ mg/day & $835(300)$ & 21.0 & $\begin{array}{c}1.28 \\
(1.21,1.36) \\
\end{array}$ & $<0.001$ & $\begin{array}{c}1.22 \\
(1.15,1.29) \\
\end{array}$ & $<0.001$ & $\begin{array}{c}1.19 \\
(1.12,1.26) \\
\end{array}$ & $<0.001$ & $\begin{array}{c}1.05 \\
(0.99,1.11) \\
\end{array}$ & 0.135 & $\begin{array}{c}1.07 \\
(1.00,1.14) \\
\end{array}$ & 0.038 \\
\hline Sodium $^{8}$ & $\begin{array}{l}\geq 1600 \mathrm{mg} / \text { day } \\
\leq 2400 \mathrm{mg} / \text { day }\end{array}$ & $1980(685)$ & 47.3 & $\begin{array}{c}1.00 \\
(0.96,1.05) \\
\end{array}$ & 0.865 & $\begin{array}{c}1.15 \\
(1.10,1.20) \\
\end{array}$ & $<0.001$ & $\begin{array}{c}1.20 \\
91.14,1.26) \\
\end{array}$ & $<0.001$ & $\begin{array}{c}1.16 \\
(1.10,1.22) \\
\end{array}$ & $<0.001$ & $\begin{array}{c}1.15 \\
(1.09,1.22) \\
\end{array}$ & $<0.001$ \\
\hline Potassium & $\geq 3500 \mathrm{mg} /$ day & $2830(772)$ & 17.7 & $\begin{array}{c}1.51 \\
(1.40,1.62) \\
\end{array}$ & $<0.001$ & $\begin{array}{c}1.37 \\
(1.28,1.47) \\
\end{array}$ & $<0.001$ & $\begin{array}{c}1.32 \\
(1.23,1.42) \\
\end{array}$ & $<0.001$ & $\begin{array}{c}1.32 \\
(1.23,1.42) \\
\end{array}$ & $<0.001$ & $\begin{array}{c}1.22 \\
(1.14,1.31) \\
\end{array}$ & $<0.001$ \\
\hline Iron & $\geq 8.7 \mathrm{mg} /$ day & $10.1(3.2)$ & 59.7 & $\begin{array}{c}1.28 \\
(1.22,1.34)\end{array}$ & $<0.001$ & $\begin{array}{c}1.25 \\
(1.19,1.32)\end{array}$ & $<0.001$ & $\begin{array}{c}1.22 \\
(1.16,1.29)\end{array}$ & $<0.001$ & $\begin{array}{c}1.24 \\
(1.18,1.31)\end{array}$ & $<0.001$ & $\begin{array}{c}1.13 \\
(1.07,1.19)\end{array}$ & $<0.001$ \\
\hline Zinc & $\begin{array}{c}\geq 9.5 \mathrm{mg} / \mathrm{day} \text { (men) } \\
\geq 7 \mathrm{mg} / \mathrm{day} \\
\text { (women) }\end{array}$ & $8.2(2.5)$ & 48.3 & $\begin{array}{c}1.28 \\
(1.22,1.34)\end{array}$ & $<0.001$ & $\begin{array}{c}1.23 \\
(1.17,1.29)\end{array}$ & $<0.001$ & $\begin{array}{c}1.22 \\
(1.16,1.28)\end{array}$ & $<0.001$ & $\begin{array}{c}1.13 \\
(1.08,1.19)\end{array}$ & $<0.001$ & $\begin{array}{c}1.01 \\
(0.96,1.06)\end{array}$ & 0.733 \\
\hline Vitamin A & $\begin{array}{c}\geq 700 \mu \mathrm{g} / \text { day (men) } \\
\geq 600 \mu \mathrm{g} / \text { day } \\
\text { (women) }\end{array}$ & $1270(1510)$ & 49.9 & $\begin{array}{c}1.10 \\
(1.06,1.15) \\
\end{array}$ & $<0.001$ & $\begin{array}{c}1.09 \\
(1.05,1.15) \\
\end{array}$ & $<0.001$ & $\begin{array}{c}1.10 \\
(1.05,1.16) \\
\end{array}$ & $<0.001$ & $\begin{array}{c}1.05 \\
(1.00,1.10) \\
\end{array}$ & 0.058 & $\begin{array}{c}1.07 \\
(1.01,1.13) \\
\end{array}$ & 0.015 \\
\hline Vitamin C & $\geq 40 \mathrm{mg} /$ day & $82.1(48.5)$ & 80.4 & $\begin{array}{c}1.70 \\
(1.57,1.83)\end{array}$ & $<0.001$ & $\begin{array}{c}1.69 \\
(1.57,1.83)\end{array}$ & $<0.001$ & $\begin{array}{c}1.62 \\
(1.50,1.75)\end{array}$ & $<0.001$ & $\begin{array}{c}1.67 \\
(1.54,1.81)\end{array}$ & $<0.001$ & $\begin{array}{c}1.28 \\
(1.19,1.37)\end{array}$ & $<0.001$ \\
\hline
\end{tabular}




\begin{tabular}{|c|c|c|c|c|c|c|c|c|c|c|c|c|c|c|}
\hline Vitamin D & $\geq 10 \mu \mathrm{g} /$ day & $3.4(2.3)$ & 1.7 & $\begin{array}{c}1.73 \\
(1.38,2.16) \\
\end{array}$ & $<0.001$ & $\begin{array}{c}1.46 \\
(1.20,1.79) \\
\end{array}$ & $<0.001$ & $\begin{array}{c}1.41 \\
(1.16,1.73) \\
\end{array}$ & 0.001 & $\begin{array}{c}1.16 \\
(0.96,1.40) \\
\end{array}$ & 0.135 & $\begin{array}{c}1.06 \\
(0.86,1.29) \\
\end{array}$ & 0.605 & \\
\hline Vitamin E & $\begin{array}{l}\geq 4 \mathrm{mg} / \text { day (men) } \\
\quad \geq 3 \mathrm{mg} / \text { day } \\
\quad \text { (women) }\end{array}$ & $8.8(3.5)$ & 98.0 & $\begin{array}{c}1.63 \\
(1.36,1.96)\end{array}$ & $<0.001$ & $\begin{array}{c}1.75 \\
(1.43,2.13)\end{array}$ & $<0.001$ & $\begin{array}{c}1.75 \\
(1.44,2.13)\end{array}$ & $<0.001$ & $\begin{array}{c}1.59 \\
(1.30,1.95)\end{array}$ & $<0.001$ & $\begin{array}{c}1.35 \\
(1.10,1.66)\end{array}$ & 0.004 & \\
\hline Folate & $\geq 400 \mu \mathrm{g} /$ day & $256(100)$ & 8.5 & $\begin{array}{c}1.37 \\
(1.26,1.50) \\
\end{array}$ & $<0.001$ & $\begin{array}{c}1.25 \\
(1.15,1.37) \\
\end{array}$ & $<0.001$ & $\begin{array}{c}1.23 \\
(1.13,1.35) \\
\end{array}$ & $<0.001$ & $\begin{array}{c}1.27 \\
(1.16,1.39) \\
\end{array}$ & $<0.001$ & $\begin{array}{c}1.09 \\
(1.00,1.20) \\
\end{array}$ & 0.063 & \\
\hline Vitamin B12 & $\geq 2.4 \mu \mathrm{g} /$ day & $6.5(5.2)$ & 93.0 & $\begin{array}{c}1.20 \\
(1.10,1.31) \\
\end{array}$ & $<0.001$ & $\begin{array}{c}1.14 \\
(1.04,1.25) \\
\end{array}$ & 0.005 & $\begin{array}{c}1.15 \\
(1.05,1.26) \\
\end{array}$ & 0.003 & $\begin{array}{c}1.05 \\
(0.95,1.15) \\
\end{array}$ & 0.359 & $\begin{array}{c}0.98 \\
(0.88,1.09) \\
\end{array}$ & 0.699 & \\
\hline Vitamin B6 & $\begin{array}{c}\geq 1.4 \mathrm{mg} / \text { day (men) } \\
\geq 1.2 \mathrm{mg} / \text { day } \\
\quad \text { (women) }\end{array}$ & $2.0(0.8)$ & 86.5 & $\begin{array}{c}1.47 \\
(1.36,1.58)\end{array}$ & $<0.001$ & $\begin{array}{c}1.40 \\
(1.30,1.50)\end{array}$ & $<0.001$ & $\begin{array}{c}1.35 \\
(1.25,1.45)\end{array}$ & $<0.001$ & $\begin{array}{c}1.45 \\
(1.34,1.57)\end{array}$ & $<0.001$ & $\begin{array}{c}1.08 \\
(1.00,1.17)\end{array}$ & 0.053 & \\
\hline Alcohol & $\begin{array}{c}\leq 14 \text { alcohol } \\
\text { units/week }\end{array}$ & $7.9(12.8)$ & 78.1 & $\begin{array}{c}0.91 \\
(0.86,0.96)\end{array}$ & $<0.001$ & $\begin{array}{c}1.15 \\
(1.09,1.22)\end{array}$ & $<0.001$ & $\begin{array}{c}1.25 \\
(1.18,1.33)\end{array}$ & $<0.001$ & $\begin{array}{c}0.93 \\
(0.87,0.98)\end{array}$ & 0.010 & $\begin{array}{c}0.96 \\
(0.90,1.02)\end{array}$ & 0.182 & \\
\hline \multicolumn{14}{|c|}{$\begin{array}{l}{ }^{1} \text { Values are OR of meeting recommendations based on a } 5 \% \text { increase in DQI-65, AHEI-2010 or HEI-2015 total score; two models presented; maximum scores available } 120 \text { points (NFDQI-65, } \\
\text { AHEI-2010 and HEI-2015 scores adjusted to maximum } 120 \text { points prior to analysis for comparison); P-values for significance of OR by logistic regression (NDNS interviewer weights applied); } \% \\
\text { energy intake refers to total energy; AHEI-2010, Alternative Healthy Eating Index-2010; AOAC, Association of Analytical Chemists; CI, confidence intervals; DQI-65, Diet Quality Index for older } \\
\text { adults; FDQI-65+PA, Food-based Diet Quality Index for older adults with physical activity; HEI-2015, Healthy Eating Index-2015; MUFA, monounsaturated fatty acids; NDNS, National Diet and } \\
\text { Nutrition Survey; NFDQI-65, Nutrient and Food-based Diet Quality Index for older adults; NFDQI-65+PA, Nutrient and Food-based Diet Quality Index for older adults with physical activity; PUFA, } \\
\text { polyunsaturated fatty acids; SFA, saturated fatty acids. } \\
\left.{ }^{2} \text { Recommendations based on nutritional requirements for UK adults } \geq 65 y \text { proposed in our recent review } 27\right) \text {. } \\
{ }^{3} \text { Nutrient recommendations set as population average; meeting recommendations classified as within } \pm 20 \% \text { of recommendation: carbohydrates } 45-55 \% \text { total energy, MUFA } 10.4-15.6 \% \text { total energy, } \\
\text { PUFA 4.8-7.2\% total energy. } \\
{ }^{4} \text { Free sugars represented by non-milk extrinsic sugars from NDNS. } \\
{ }^{5} \text { Results from } 800 \text { subjects due to non-response for body weight measurement. } \\
{ }^{7} \text { Nutrient intake approximate conversion from non-starch polysaccharide fibre to AOAC; conversion factor } 1.33 \text { as used in NDNS }{ }^{(54)} \text {. } \\
{ }^{8} \text { Adjusted for underreporting in analysis based on average underreporting of } 25 \% \text { in NDNS from comparison with urinary sodium; meeting recommendations based on } 1200 \text { mg/day-2000 mg/day } \\
\text { instead of } 1600 \mathrm{mg} / \text { day-2400 mg/day. }\end{array}$} & $2.0 \pm 0.8$ \\
\hline
\end{tabular}


Table 4. Association between DQI-65s, HEI-2015 and AHEI-2010 scores and biomarkers of nutrient intake for subjects aged $\geq 65 \mathrm{y}$ from UK NDNS years $2-6^{1}$

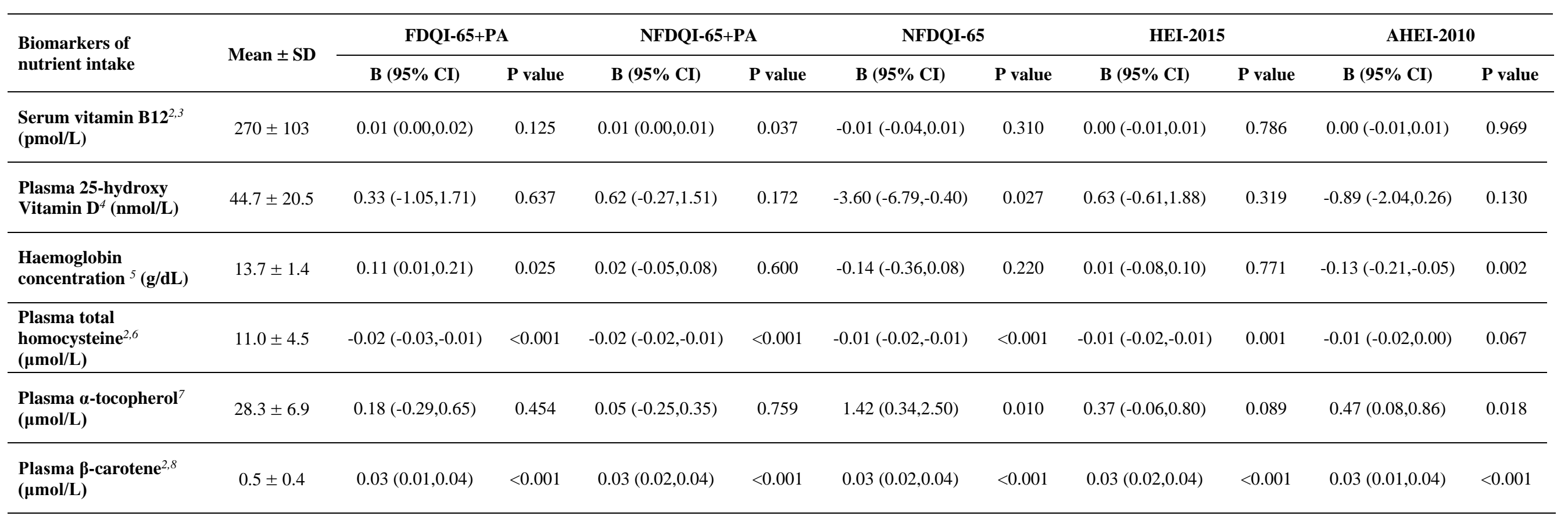

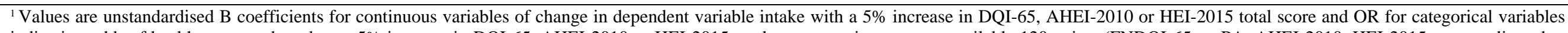

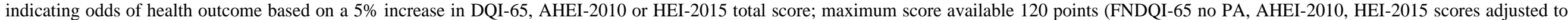

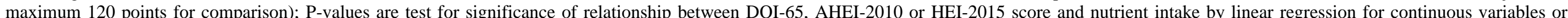

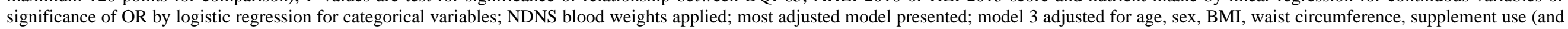

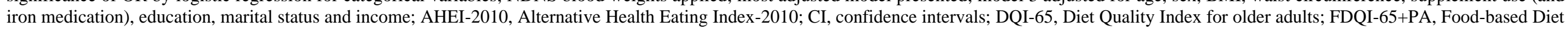

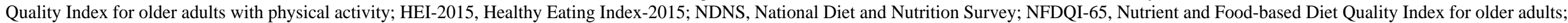

NFDQI-65+PA, Nutrient and Food-based Diet Quality Index for older adults with physical activity; OR, odds ratio.

${ }^{2}$ Dependent variable transformed by $\log _{10}$ to improve normality; unstandardised B coefficient and CI are log-increase in variable by $5 \%$ increase in total score.

${ }^{3} n=382$ 
${ }^{4} n=374$

${ }^{5} n=326$

${ }^{6} n=306$

${ }^{7} n=378$

${ }^{8} n=377$

Table 4. Associations between DQI-65s, HEI-2015 and AHEI-2010 scores and health status measures and metabolic markers for subjects aged $\geq 65 \mathrm{y}$ from

UK NDNS years 2-6 ${ }^{1}$

\begin{tabular}{|c|c|c|c|c|c|c|c|c|c|c|c|}
\hline \multirow[b]{2}{*}{ Health marker } & \multirow[b]{2}{*}{ Mean \pm SD } & \multicolumn{2}{|c|}{ FDQI-65+PA } & \multicolumn{2}{|c|}{ NFDQI-65+PA } & \multicolumn{2}{|l|}{ NFDQI-65 } & \multicolumn{2}{|l|}{ HEI-2015 } & \multicolumn{2}{|c|}{ AHEI-2010 } \\
\hline & & B $(95 \%$ CI $)$ & $P$ value & B (95\% CI) & $\begin{array}{c}\mathbf{P} \\
\text { value }\end{array}$ & B $(95 \%$ CI $)$ & $\begin{array}{c}\mathbf{P} \\
\text { value }\end{array}$ & B $(95 \%$ CI $)$ & $\begin{array}{c}\mathbf{P} \\
\text { value }\end{array}$ & B $(95 \%$ CI $)$ & $\begin{array}{c}\mathbf{P} \\
\text { value }\end{array}$ \\
\hline $\mathrm{BMI}^{2}\left(\mathbf{k g} / \mathbf{m}^{2}\right)$ & $27.8 \pm 5.0$ & $-0.20(-0.33,-0.07)$ & 0.003 & $-0.29(-0.42,-0.15)$ & $<0.001$ & $-0.25(-0.38,-0.11)$ & $<0.001$ & $-0.26(-0.40,-0.13)$ & $<0.001$ & $-0.30(-0.45,-0.16)$ & $<0.001$ \\
\hline $\begin{array}{l}\text { Waist circumference }{ }^{3} \\
(\mathbf{c m})\end{array}$ & $96.3 \pm 13.4$ & $-0.20(-0.39,-0.02)$ & 0.030 & $-0.90(-1.24,-0.56)$ & $<0.001$ & $-0.80(-1.15,-0.44)$ & $<0.001$ & $-0.99(-1.36,-0.62)$ & $<0.001$ & $-0.98(-1.38,-0.58)$ & $<0.001$ \\
\hline $\begin{array}{l}\text { Number of prescribed } \\
\text { medicines }^{4,16}\end{array}$ & $4.3 \pm 2.8$ & $-0.25(-0.34,-0.17)$ & $<0.001$ & $-0.22(-0.30,-0.14)$ & $<0.001$ & $-0.10(-0.20,-0.01)$ & 0.002 & $-0.19(-0.28,-0.09)$ & $<0.001$ & $-0.14(-0.24,-0.04)$ & 0.005 \\
\hline $\mathbf{S B P}^{5}(\mathbf{m m H g})$ & $135 \pm 16.8$ & $-0.01(-0.58,0.56)$ & 0.966 & $-0.03(-0.62,0.55)$ & 0.910 & $-0.19(-0.79,0.42)$ & 0.549 & $0.52(-0.10,1.14)$ & 0.102 & $0.56(-0.11,1.23)$ & 0.101 \\
\hline $\mathrm{DBP}^{5}(\mathbf{m m H g})$ & $71.4 \pm 9.9$ & $-0.07(-0.40,0.25)$ & 0.664 & $-0.58(-0.91,-0.25)$ & 0.001 & $-0.77(-1.11,-0.43)$ & $<0.001$ & $-0.14(-0.50,0.21)$ & 0.430 & $-0.27(-0.65,0.11)$ & 0.168 \\
\hline $\mathrm{TC}^{6}(\mathrm{mmol} / \mathrm{L})$ & $5.1 \pm 1.2$ & $0.03(-0.02,0.07)$ & 0.240 & $0.00(-0.05,0.04)$ & 0.951 & $0.00(-0.05,0.05)$ & 0.934 & $0.00(-0.05,0.05)$ & 0.978 & $0.01(-0.04,0.06)$ & 0.691 \\
\hline LDL-C $\mathbf{C}^{7,15}(\mathbf{m m o l} / \mathbf{L})$ & $3.1 \pm 1.1$ & $0.01(0.00,0.01)$ & 0.106 & $0.00(0.00,0.01)$ & 0.400 & $0.00(0.00,0.01)$ & 0.536 & $0.00(-0.01,0.01)$ & 0.761 & $0.00(-0.01,0.01)$ & 0.628 \\
\hline HDL-C $\mathbf{C}^{6,15}(\mathbf{m m o l} / \mathbf{L})$ & $1.5 \pm 0.5$ & $0.01(0.00,0.01)$ & 0.012 & $0.00(0.00,0.01)$ & 0.666 & $0.00(-0.01,0.01)$ & 0.909 & $0.00(0.00,0.01)$ & 0.279 & $0.00(0.00,0.01)$ & 0.230 \\
\hline TC:HDL-C ratio & $3.5 \pm 1.0$ & $0.00(-0.01,0.00)$ & 0.112 & $0.00(-0.01,0.01)$ & 0.739 & $0.00(-0.01,0.01)$ & 0.950 & $0.00(-0.01,0.00)$ & 0.282 & $0.00(-0.01,0.00)$ & 0.420 \\
\hline $\mathbf{T G}^{7,15}(\mathbf{m m o l} / \mathbf{L})$ & $1.2 \pm 0.6$ & $-0.01(-0.02,0.00)$ & 0.004 & $-0.01(-0.02,0.00)$ & 0.055 & $-0.01(-0.02,0.00)$ & 0.069 & $-0.01(-0.02,0.00)$ & 0.023 & $-0.01(-0.02,0.00)$ & 0.059 \\
\hline
\end{tabular}




\begin{tabular}{|c|c|c|c|c|c|c|c|c|c|c|c|}
\hline $\mathbf{C R P}^{8,15,16}(\mathbf{m g} / \mathbf{L})$ & $4.7 \pm 7.4$ & $-0.04(-0.06,-0.02)$ & $<0.001$ & $-0.06(-0.08,-0.05)$ & $<0.001$ & $-0.04(-0.06,-0.02)$ & $<0.001$ & $-0.06(-0.07,-0.04)$ & $<0.001$ & $-0.05(-0.07,-0.03)$ & $<0.001$ \\
\hline $\begin{array}{l}\text { Fasting glucose } \mathbf{e}^{9,16} \\
(\mathbf{m m o l} / \mathbf{L})\end{array}$ & $5.3 \pm 0.9$ & $-0.01(-0.05,0.03)$ & 0.511 & $0.00(-0.05,0.04)$ & 0.869 & $0.01(-0.04,0.05)$ & 0.831 & $0.00(-0.04,0.04)$ & 0.953 & $0.03(-0.02,0.07)$ & 0.274 \\
\hline $\mathbf{H b A 1}^{10,16}(\%)$ & $5.8 \pm 0.4$ & $0.00(-0.02,0.02)$ & 0.821 & $0.01(-0.01,0.03)$ & 0.451 & $0.01(-0.01,0.03)$ & 0.507 & $0.01(-0.01,0.03)$ & 0.352 & $0.01(-0.01,0.03)$ & 0.420 \\
\hline \multirow{2}{*}{ Health marker } & \multirow{2}{*}{$\begin{array}{c}\text { Proportion } \\
\text { meeting } \\
\text { criteria }(\%)\end{array}$} & \multicolumn{2}{|c|}{ FDQI-65+PA } & \multicolumn{2}{|c|}{ NFDQI-65+PA } & \multicolumn{2}{|c|}{ NFDQI-65 } & \multicolumn{2}{|l|}{ HEI-2015 } & \multicolumn{2}{|c|}{ AHEI-2010 } \\
\hline & & OR $(95 \%$ CI $)$ & $P$ value & OR $(95 \%$ CI $)$ & $\begin{array}{c}\mathbf{P} \\
\text { value }\end{array}$ & OR $(95 \% \mathrm{CI})$ & $\begin{array}{c}\mathbf{P} \\
\text { value }\end{array}$ & OR $(95 \%$ CI $)$ & $\begin{array}{c}\mathbf{P} \\
\text { value }\end{array}$ & OR $(95 \% \mathrm{CI})$ & $\begin{array}{c}\mathbf{P} \\
\text { value }\end{array}$ \\
\hline \multirow{2}{*}{$\begin{array}{l}\text { Self-assessed health } \\
\text { Good or very good }\end{array}$} & \multirow{2}{*}{72.2} & $1.18(1.08,1.29)$ & $<0.001$ & $1.12(1.03,1.22)$ & 0.010 & $1.03(0.95,1.13)$ & 0.471 & $1.14(1.04,1.24)$ & 0.005 & $0.98(0.89,1.09)$ & 0.748 \\
\hline & & $1.19(1.08,1.31)$ & $<0.001$ & $1.12(1.02,1.23)$ & 0.022 & $1.05(0.96,1.16)$ & 0.301 & $1.15(1.05,1.27)$ & 0.004 & $1.00(0.90,1.12)$ & 0.960 \\
\hline Longstanding illness $^{12}$ & 59.4 & $0.95(0.88,1.02)$ & 0.155 & $0.92(0.85,0.99)$ & 0.036 & $0.98(0.91,1.06)$ & 0.581 & $0.95(0.88,1.03)$ & 0.204 & $1.01(0.93,1.10)$ & 0.841 \\
\hline $\begin{array}{l}\text { Hypertension }^{5} \\
\text { SBP }>140 \mathrm{mmHg} \text { or } \\
\text { DBP }>90 \mathrm{mmHg} \text { or } \\
\text { Taking BP lowering } \\
\text { medication }\end{array}$ & 57.2 & $1.01(0.92,1.10)$ & 0.888 & $1.06(0.97,1.16)$ & 0.199 & $1.05(0.96,1.16)$ & 0.271 & $1.06(0.96,1.16)$ & 0.239 & $1.03(0.93,1.14)$ & 0.612 \\
\hline
\end{tabular}

\section{Metabolic syndrome ${ }^{14}$}

$\geq 3$ of the following:

Waist circumference

$>102 \mathrm{~cm}$ (men) and

$>88 \mathrm{~cm}$ (women)

$\mathrm{TG}>1.7 \mathrm{mmol} / \mathrm{L}$

HDL-C $<1.03$ (men) and

$<1.29 \mathrm{mmol} / \mathrm{L}$ (women)

BP $>130 / 85 \mathrm{mmHg}$

Fasting glucose

$>6.1 \mathrm{mmol} / \mathrm{L}$

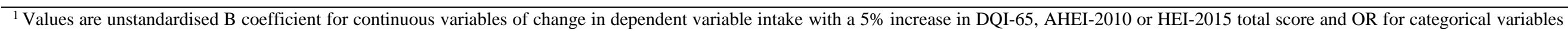

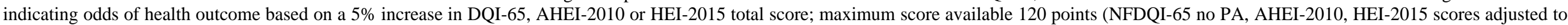

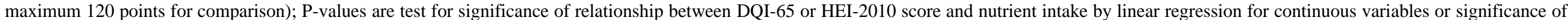

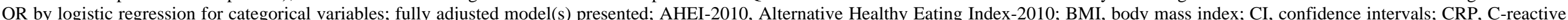

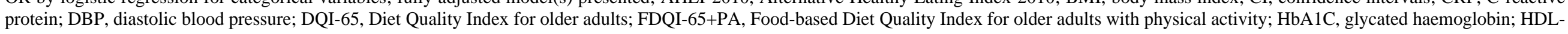




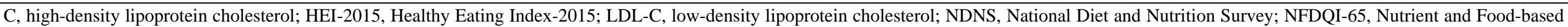

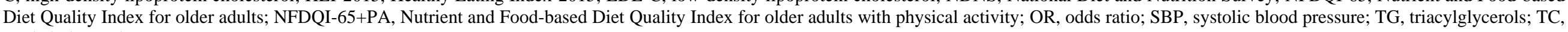
total cholesterol.

${ }^{2} n=767$; NDNS interviewer weights applied; adjusted for age, sex, smoking, education, marital status and income.

${ }^{3} n=566$; NDNS nurse weights applied; adjusted for age, sex, BMI, smoking, education, marital status and income.

${ }^{4} n=471 ;$ NDNS nurse weights applied.

${ }^{5} n=419$; NDNS nurse weights applied; adjusted for age, sex, BMI, waist circumference, blood pressure medication (for SBP and DBP), smoking, education, marital status and income.

${ }^{6} n=333$; NDNS blood weights applied; adjusted for age, sex, BMI, waist circumference, lipid medication, smoking, education, marital status and income.

$7 n=330$; NDNS blood weights applied; adjusted for age, sex, BMI, waist circumference, lipid medication, smoking, education, marital status and income.

${ }^{8} n=381$; NDNS blood weights applied.

${ }^{9} n=336$; known diabetics excluded; NDNS blood weights applied.

${ }^{10} n=333$; known diabetics excluded; NDNS blood weights applied.

${ }^{11} n=443$; NDNS nurse weights applied.

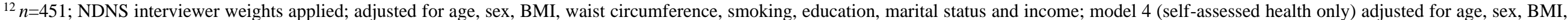
waist circumference, smoking, education, marital status, income and longstanding illness.

${ }^{13} n=291$; NDNS interviewer weights applied.

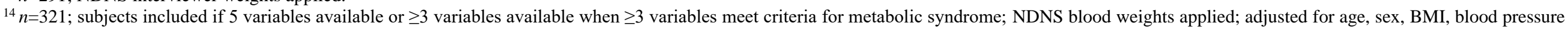
medication, lipid medication, smoking, education, marital status and income.

${ }^{15} \log 10$ transformation applied to improve normality; unstandardized B coefficient and CI is log-increase in variable by $5 \%$ change in dietary score.

${ }^{16}$ Adjusted for age, sex, BMI, waist circumference, smoking, education, marital status and income. 
Figure 1. Mean \pm SEM score per component of FDQI-65+PA and NFDQI-65+PA calculated using data for adults aged $\geq 65 \mathrm{y}$ from UK National Diet and Nutrition Survey (NDNS) rolling programme Years 2-6 (n=871). NFDQI-65 component scores identical to NFDQI-65+PA, except for physical activity which is not included in the NFDQI-65. Maximum score of 10 available per component. NDNS interviewer weights applied. FDQI-65+PA, Food-based Diet Quality Index for older adults with physical activity; NFDQI-65, Nutrient and Food-based Diet Quality Index for older adults; NFDQI-65+PA, Nutrient and Food-based Diet Quality Index for older adults with physical activity. 
Figure 2. Mean \pm SEM score per component of HEI-2015 calculated using data for adults aged $\geq 65 y$ from UK National Diet and Nutrition Survey (NDNS) rolling programme Years 2-6 ( $\mathrm{n}=871)$. Maximum score of 5 available for fruit, whole fruit, vegetables, greens and beans, total protein, and seafood and plant protein components. Maximum score of 10 available for wholegrains, dairy, fatty acids, refined grains, sodium, added sugars and SFA components. NDNS interviewer weights applied. HEI-2015, Healthy Eating Index-2015. 
Figure 3. Mean \pm SEM score per component of AHEI-2010 calculated using data for adults aged $\geq 65 y$ from UK National Diet and Nutrition Survey (NDNS) rolling programme Years 2-6 ( $\mathrm{n}=871)$. Maximum score of 10 available per component. NDNS interviewer weights applied. AHEI-2010, Alternative Healthy Eating Index-2010. 